This item was submitted to Loughborough's Institutional Repository (https://dspace.lboro.ac.uk/) by the author and is made available under the following Creative Commons Licence conditions.

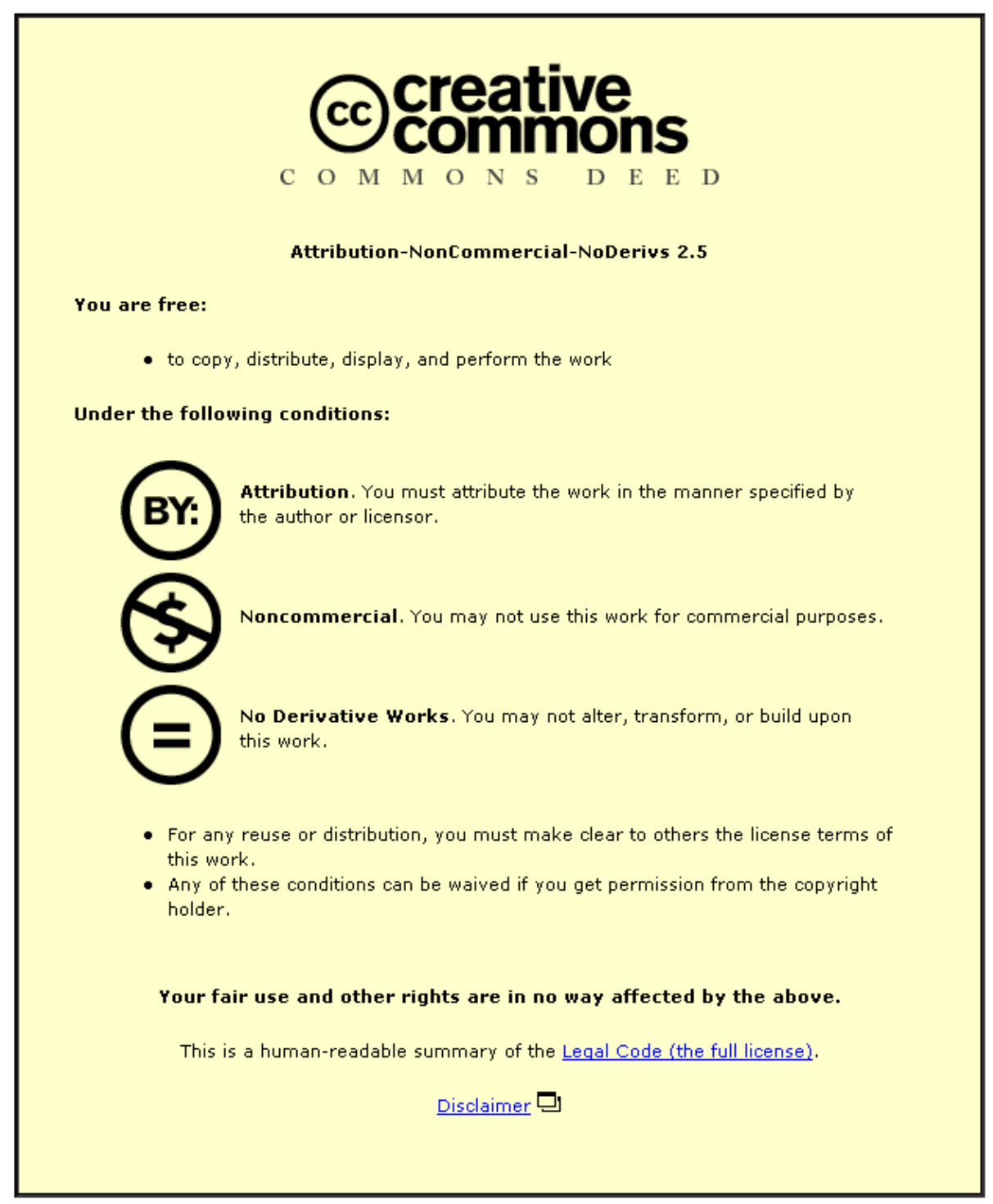

For the full text of this licence, please go to: http://creativecommons.org/licenses/by-nc-nd/2.5/ 


\title{
Design of an airlift loop bioreactor and pilot scales studies with fluidic oscillator induced microbubbles for growth of a
}

\section{microalgae Dunaliella salina}

William B. Zimmerman ${ }^{1 *}$, Mohammad Zandi ${ }^{2}$, HC Hemaka Bandulasena ${ }^{1}$, Václav Tesař ${ }^{3}$, D. James Gilmour ${ }^{4}$, Kezhen Ying ${ }^{1}$

${ }^{1}$ Department of Chemical and Biological Engineering, University of Sheffield, Mappin

Street, Sheffield S1 3JD, United Kingdom

${ }^{2}$ TATA Steel RD\&T, Swinden Technology Centre, Moorgate, Rotherham,

South Yorkshire S60 3AR, UK

${ }^{3}$ Institute of Thermomechanics, Academy of Sciences of the Czech Republic, Prague, Czech

Republic.

${ }^{4}$ Department of Molecular Biology and Biotechnology, University of Sheffield, Firth Court, Western Bank, Sheffield S10 2TN, United Kingdom

*Corresponding author. Email: w.zimmerman@shef.ac.uk

\begin{abstract}
This study was conducted to test the feasibility of growing microalgae on steel plant exhaust gas, generated from the combustion of offgases from steel processing, which has a high $\mathrm{CO}_{2}$ content. Two field trials of batch algal biomass growth, mediated by microbubble transfer processes in an airlift loop bioreactor showed only steady growth of biomass with $100 \%$ survival rate. The gas analysis of $\mathrm{CO}_{2}$ uptake in the 2200 liter bioreactor showed a specific uptake rate of $0.1 \mathrm{~g} /$ liter / $\mathrm{hr}$, an average $14 \%$ of the $\mathrm{CO}_{2}$ available in the exhaust gas with a $23 \%$ composition of $\mathrm{CO}_{2}$. This uptake led to a steady production of chlorophyll and total lipid constituency in the bioreactor, and an accelerating exponential growth rate of biomass, with a top doubling time of 1.8 days. The gas analysis also showed anti-correlation of $\mathrm{CO}_{2}$ uptake and $\mathrm{O}_{2}$ production, which along with the apparent stripping of the $\mathrm{O}_{2}$ to the equilibrium level by the microbubbles, strongly suggests that the bioreactor is not mass transfer limited, nor $\mathrm{O}_{2}$ inhibited. Removing $\mathrm{O}_{2}$ inhibition results in high growth rates and high density of biomass.
\end{abstract}

Keywords: nanobubbles, microbubbles, nonlinear wave dynamics, microfluidics

\section{Introduction}

It is well known that algae fix $\mathrm{CO}_{2}$, and must do so by extracting it from aqueous solution in which it is dissolved, typically from transfer from the atmosphere at 380ppm. With such low levels of $\mathrm{CO}_{2}$ available, it is possible that mass transfer will be the limiting factor in algal 
growth. In order to take advantage of the high $\mathrm{CO}_{2}$ content, around $20 \%$ for combustion processes, in exhaust gases, it is conventional wisdom that a strain of algae must be found that is tolerant to high concentrations of dissolved $\mathrm{CO}_{2}$. This article starts from the opposite premise, that high $\mathrm{CO}_{2}$ concentration is in general favourable to algal metabolism, but the barrier to high density and high growth rates is actually dissolved $\mathrm{O}_{2}$ levels. In order to demonstrate this, the environment of the algal bioculture must be engineered to extract the dissolved $\mathrm{O}_{2}$ produced by the bioculture.

In a preliminary study, Hanotu (2009) conducted algal growth experiments with microbubbles (c. 500 microns in diameter) and fine bubbles (1-2 mm), in an airlift loop bioreactor (ALB) as designed by Zimmerman et al. (2009). The airlift loop effect results in rapid mixing at very low energy cost due to the supply of microbubbles, and also very high transfer rates. The 250 liter bioreactor was fitted with a 9inch membrane diffuser with $1 \mathrm{~mm}$ slits (supplied by Suprafilt, Rochdale UK), equipped for the fluidic oscillation mechanism for microbubble generation (Zimmerman et al. 2008, 2010). With an hour a day dosing with 5\% $\mathrm{CO}_{2} / 95 \% \mathrm{~N}_{2}$ at 80 litres / min, Hanotu (2009) demonstrated steady growth during a two week study with the oscillation induced microbubbles, but a plateau and then death phases with only the fine bubble dosing without the oscillation. The overall growth rate was estimated as $30 \%$ higher for the microbubble mediated algal growth of Dunaliella salina over the fine bubble mediated growth. Both studies were conducted under identical artificial lighting conditions. The study suggested that since both microbubble and fine bubble mediation resulted in $\mathrm{CO}_{2}$ saturation of the liquid phase, the greater viability of the microbubble mediation was due to some other effect than the rate of $\mathrm{CO}_{2}$ dosing being greater. The airlift loop design gives rise to two possibilities - (1) the microbubbles are better at suspending the algae due to the flotation effect (see Grammatika and Zimmerman, 2001) and hence maintaining that algae are exposed to the lighting and do not preferentially drop into stagnant zones and die; (2) that microbubbles extract the $\mathrm{O}_{2}$ released by the algae and thus remove the inhibition on their growth, and eventual toxic effects of dissolved $\mathrm{O}_{2}$ build up.

This paper reports on two pilot scale tests with heavy dosing on $\mathrm{CO}_{2}$ from steel plant stack gas of $D$. salina growth in a larger (2200 liter) ALB with smaller microbubbles (c. 300 microns) and a very high gas phase hold up (estimated as $40 \%$ in the plume). The trials were designed to address the issues raised in the preliminary study:

- Does high concentration of $\mathrm{CO}_{2}$ dosed from the gas, along with trace impurities from the steel process exhaust gas, lead to a robust, viable algal bioculture, particularly under longer dosing conditions?

- Does stripping of the $\mathrm{O}_{2}$ occur, and does that lead to greater growth rates, or is the ALB mass transfer limited and $\mathrm{O}_{2}$ inhibited?

- Does the suspension effect hold at higher volumes of liquid in the bioreactor and higher densities of algal biomass within the reactor?

The paper is organized as follows.

Section 2 describes the methods and materials for the design of the fluidic oscillator microbubble generation system used, the characterization of the microbubble cloud generated 
at the maximum flow rate used in the pilot trials, the design of the pilot scale airlift loop bioreactor, how $D$. salina was pre-cultured in the 250 liter lab scale ALB, the biochemical analysis of the samples from the two field trials, and the gas monitoring and analysis methods. Section 3 describes the results of the field trials, and discusses their analysis. In Section 4 , conclusions are drawn.

\section{\$1.1 About the pilot scale field trials}

Due to the lack of a continuous source of $\mathrm{CO}_{2}$ in our labs, a partner organization (TataSteel) is sought with a continuous supply of high $\mathrm{CO}_{2}$ concentration gas streams. We were initially concerned that finding a robust strain of microalgae that would survive the harsh constituents and potential trace materials from the steel processing offgases used in the power plant at TataSteel's Scunthorpe site. The trials were conducted from 27 April to 5 May 2010 (Trial 1) with ten days of dosing, and from 6-22 September 2010 (Trial 2) with 17 days of dosing. Trial 1 was envisaged as a learning period, both exploratory about the operation of the bioreactor and about the possible pitfalls in the strategy.

We had planned to control for temperature by using adjusting the volumetric flow rate of hot stack gas through the bioreactor, as a steel plant has many sources of waste heat that are valuable in the target range of $25-30^{\circ} \mathrm{C}$. Unfortunately, we did not realize that the high humidity of the stack gas would interfere with the performance of our compressor. We constructed a makeshift condenser unit, but were never able to conduct runs of longer than four hours with that compressor during Trial 1. The weather was poor during that period, with partially cloudy, low sunlight days as shown in Table 1. Table 2 gives a similar set of information for Trial 2. Clearly, ambient lighting was far better for Trial 2, but also, due to learning about the operating conditions, we were able to conduct trials for 10-12 hours per day of dosing, and at the perceived best operating conditions found from Trial 1. We also used some artificial heating to try to maintain the bioreactor temperature nearer to the target of $25^{\circ} \mathrm{C}$. This paper is not intended to compare the trials, but rather to assess our hypotheses about the viability of microalgae when the gas transfer processes are mediated by microbubbles with high transfer rates.

Table 1 Weather and reactor conditions conditions from Trial 1

\begin{tabular}{|c|c|c|c|c|c|c|}
\hline Day & $\begin{array}{l}\text { Light } \\
\text { intensity, } \\
k L u x\end{array}$ & $\begin{array}{l}\text { 24h Mean } \\
\text { Temperature, } \\
{ }^{\circ} \mathrm{C}\end{array}$ & $\begin{array}{l}\text { Mean } \\
\text { Temperature } \\
\text { during } \\
\text { process, } \\
{ }^{\circ} \mathrm{C}\end{array}$ & $\begin{array}{l}\text { Gas } \\
\text { Inlet } \\
\text { Flow } \\
\text { rate, } \\
\text { l/min }\end{array}$ & $\begin{array}{l}\text { Bioreactor } \\
\text { Temperature, } \\
{ }^{\circ} \mathrm{C}\end{array}$ & $\begin{array}{l}\mathrm{CO}_{2} \text { inlet } \\
\text { Temperature, } \\
{ }^{\circ} \mathrm{C}\end{array}$ \\
\hline $27 / 04 / 2010$ & 30.8 & 6 & 17.8 & 80 & 17.8 & 22.9 \\
\hline $28 / 04 / 2010$ & 36.5 & 9 & 18.7 & 80 & 18.7 & 21.1 \\
\hline
\end{tabular}




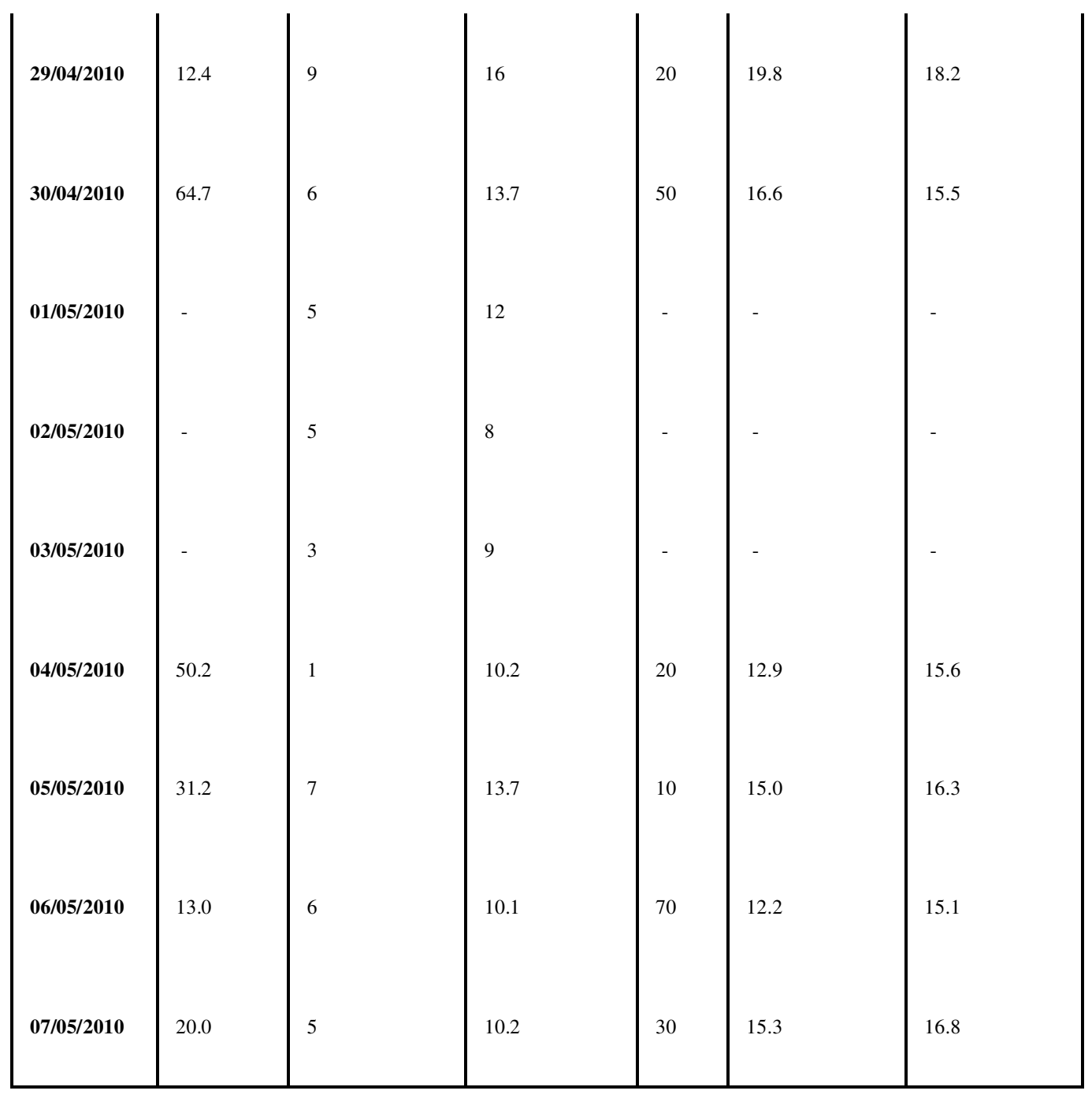

Table 2 Weather and bioreactor conditions from Trial 2.

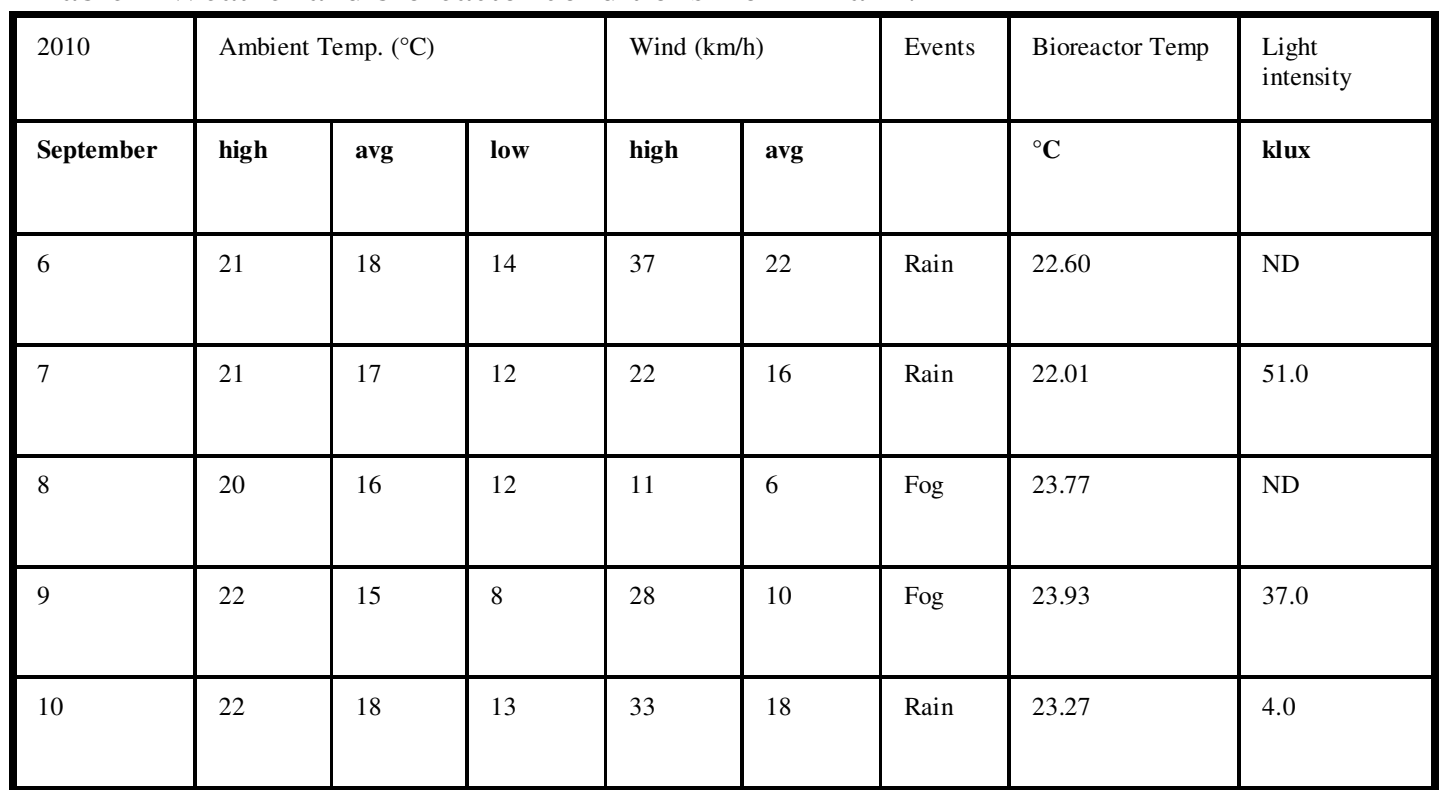




\begin{tabular}{|c|c|c|c|c|c|c|c|c|}
\hline 11 & 22 & 17 & 12 & 37 & 21 & Rain & 26.02 & ND \\
\hline 12 & 12 & 11 & 10 & 11 & 8 & & 25.61 & ND \\
\hline 13 & 19 & 16 & 13 & 43 & 22 & Rain & 22.89 & 4.8 \\
\hline 14 & 20 & 16 & 12 & 46 & 28 & Rain & 23.15 & 3.8 \\
\hline 15 & 16 & 14 & 11 & 48 & 29 & Rain & 21.48 & 9.8 \\
\hline 16 & 17 & 14 & 10 & 35 & 21 & Rain & 18.69 & 4.0 \\
\hline 17 & 16 & 12 & 8 & 30 & 17 & & 18.88 & 4.0 \\
\hline 18 & 16 & 12 & 7 & 26 & 14 & & 20.10 & ND \\
\hline 19 & 12 & 12 & 11 & 18 & 16 & & 20.41 & ND \\
\hline 20 & 20 & 17 & 14 & 33 & 22 & & 20.40 & 4.5 \\
\hline 21 & 21 & 14 & 8 & 20 & 8 & Fog & 21.21 & 4.8 \\
\hline 22 & 22 & 17 & 12 & 26 & 10 & Rain & 21.90 & ND \\
\hline
\end{tabular}

\section{Methods and materials}

In this section, the design of the fluidic oscillator and microbubble generation system used in the pilot scale bioreactor is presented, along with the layout of the ALB system in a 2200 liter rectangular prism tank. The biochemical analysis and gas monitoring and analysis methodologies are presented. In both trials, an innoculum of microalgae bioculture was prepared in the lab. Due to logistical problems with renovations in the lab, it was not possible to have comparable innoculum biomass concentration in both trials. The second innoculum was much less dense than the first.

\section{\$2.1 Fluidic oscillator design}

The fluidic oscillator is an essential element of a novel airlift loop bioreactor as introduced by Zimmerman et al. (2009). It generates nearly monodispersed, uniformly spaced and regularly released microbubble clouds with significant influence on the mass transfer and mixing efficiencies. It is inserted into the gas supply where its task is to limit the growth of the bubbles produced by percolation by restricting the available growth time to one half of the oscillation period. In principle, this limitation might be achieved by a gas flow oscillation 
generator with moving mechanical components. This would be essentially a mechanically operated valve, periodically opened and closed. In fact, this may be a good choice for initial laboratory testing, because mechanical oscillation generator (perhaps with rotating rather than oscillating mechanical component, since its inertia would probably limit the achievable oscillation frequency) is easier to set up than the pure fluidic solution. On the other hand, the no-moving-part fluidics is essential for the success of operationally used bioreactors because of its overall simplicity, reliability, no need for electric energy supply, robustness, and -last but not least - low cost.

Fluidic oscillators (Tesar, 2007) are supplied with steady fluid flow, which they convert into a pulsatory or even alternating flow at their outputs. In the absence of moving components, the oscillation is generated in a fixed-geometry cavity as a consequence of some inherent instability in the fluid. The subject of hydrodynamic instabilities is quite wide; only some of them are of importance in the present context. These involve two important features - even though sometimes not immediately recognisable:

a) There is a certain weak spot in the flow. An action at a low power relative to the flowfield power levels is sufficient, if applied in the sensitive region, to cause large-scale changes in the character of the flow.

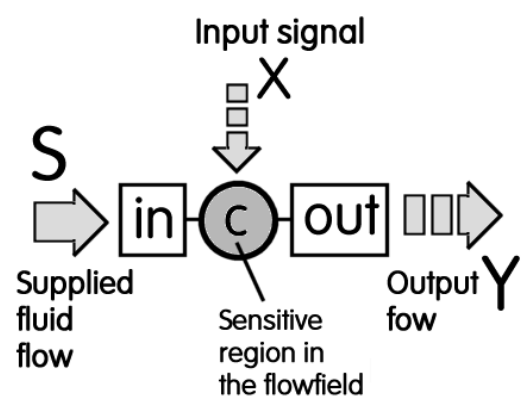

Fig. 1 The basic principle of the fluidic amplification. Undisturbed fluid flow $S$ into the domain is acted upon by a quite weak input signal $X$ in the sensitive region. This causes a substantial change in the character of the output flow $\mathrm{Y}$.

The task of the fluidic amplifier designer is to develop such geometry of the cavities inside a solid body which would exhibit such sensitivity in an as high as possible degree. An example - not actually used in the present case - is the transition into turbulence and the consequent complete change in the character of the flow in response to a feeble acoustic signal. This is actually too sensitive and difficult to tame for engineering purposes. A less well known mechanism, actually used by the present authors, is the large change of the flow direction of a jet of fluid is acted upon immediately downstream from the exit of the nozzle in which it is formed.

a) There is a feedback loop. This means a certain part of the output flow can act on the sensitive region of its flowfield, and thus influence its own existence or magnitude of its parameters. The feedback action may be either stabilising or de-stabilising. In an oscillator we use the latter case. 


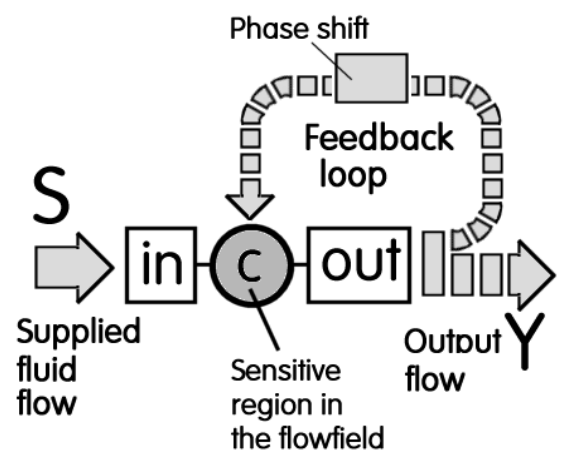

Fig. 2 The basic principle of the fluidic oscillator. a small proportion of the power available in an increasing output flow $\mathrm{Y}$ has an opportunity to act, on the sensitive region. Because of the amplification property, it suffices for decreasing the output flow. This, however, also reduces through the feedback the damping effect in the weak spot, so that the output flow starts to increase again - the increase and decrease thus alternate periodically.

In fact, the feedback action is somewhat more complicated. It must give the amplifier an opportunity to settle temporarily to a particular (either open or closed) state before it is forced to move back. This is achieved by the phase shifter in the loop. The magnitude of the shift also determines the oscillation frequency. Another complication is the character of the loop, which in simplest cases is a physically present external feedback channel, but in many oscillators may be some internal vortical flowfield difficult to identify. An example of identification of such internal feedback mechanism is described in Tesar (2009).

With the principle of the oscillator being as simple as this, designing a successful fluidic amplifier with the proper feedback to oscillate as desired may seem to be easy. In reality, this is a task generally requiring much effort and trouble. The amplification gains of

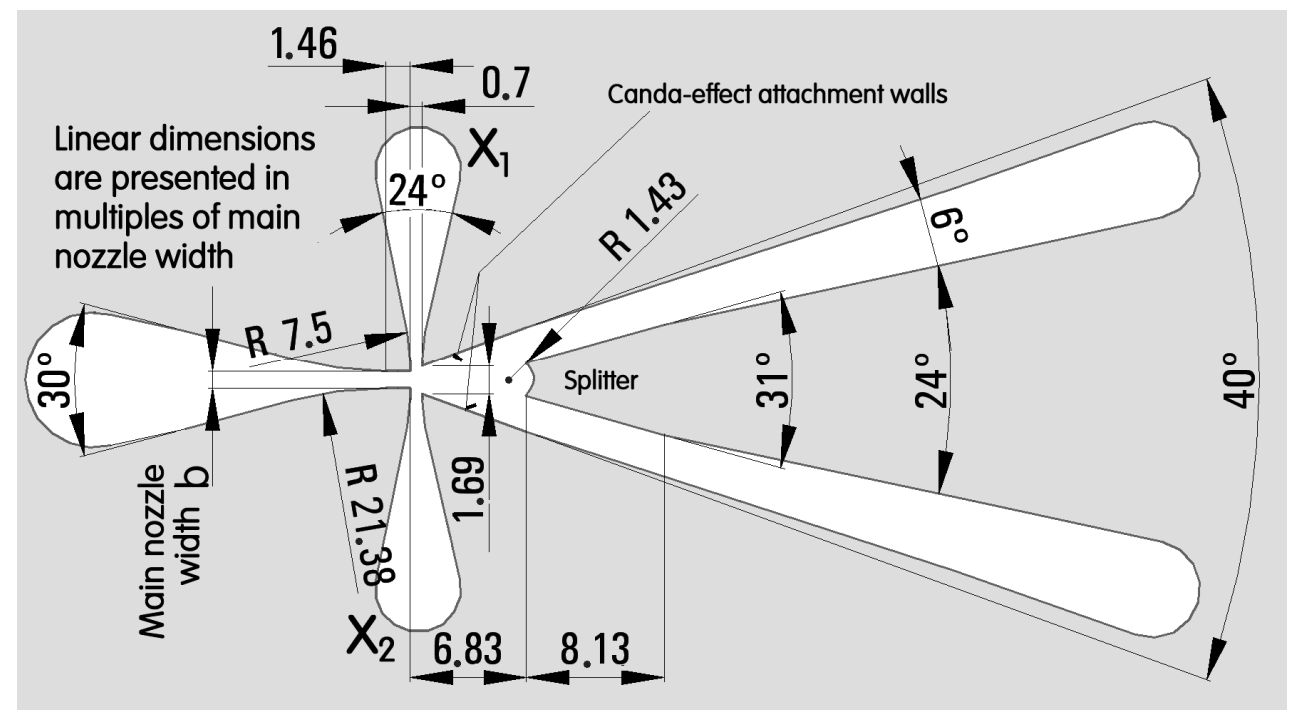

Fig. 3 Geometry of a bistable fluidic diverter developed from the design described in Tesar et al. (2006) and used in the bioreactor. As a valve, it is controlled by short switching pulses brought alternatively into the control 
terminals $\mathrm{X}_{1}$ or $\mathrm{X}_{2}$, which in the oscillator are connected by the feedback loop tube. Note the bi-cuspid splitter nose intended to generate a stabilising internal feedback flow.

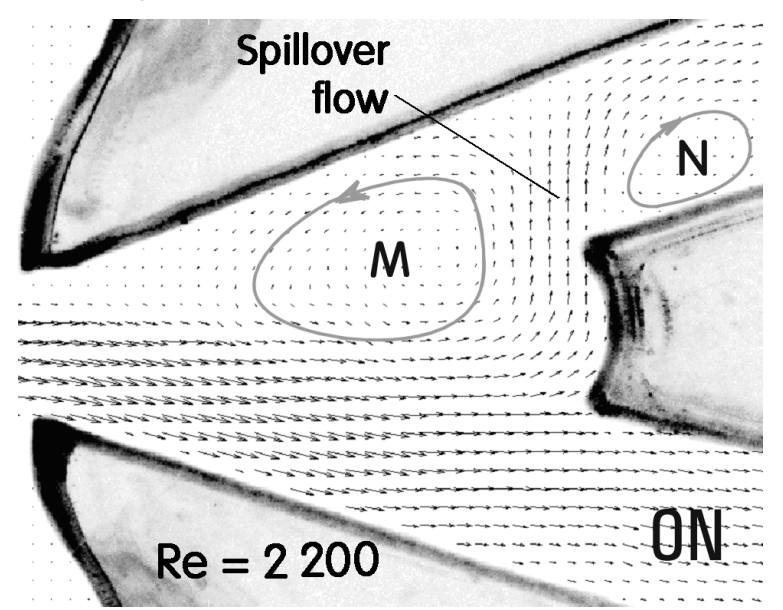

Fig. 4 Particle image velocimetry investigations of the typical flowfield in the fluidic valve with zero control flows show considerable spillover flow into the OFF collector past the two trapped standing vortices, the stabilising feedback vortex $\mathrm{M}$ and the OFF diffuser entrance blocking vortex $\mathrm{N}$.

amplifiers designed without previous experience tend to be small. Then the oscillation may refuse to start at all or exhibits a wrong frequency. This is because apart from the intentional, feedback loop there may be in action internal, wholly undesirable but difficult to identify feedbacks, perhaps in the form of acoustic pressure transmitted through the cavities by wave processes. In general, it is true that "... fluidic design is a black art, and there are few prospering practitioners of this art...". Most current designs therefore simply copy successful earlier geometries. In their bioreactor oscillator, the present authors used the bistable Coanda-effect (Coanda, 1936) amplifier geometry as presented in Fig. 3 (Tesar et al. 2006). It was originally designed as early as in 1971 for an air conditioning system (Tesar, 1975) and later found in 1983 well performing in fluidics-switched hot gas cleaning (Perera and Syred, 1983). There are two alternative feedback layouts: the fact that there are two outputs and two control terminals suggests - according to Warren (1962) - using two feedback channels, one on each side of the amplifier. The other, less obvious but simpler oscillator layout first discussed by Spyropulos (1964) simply connects by the feedback channel the two control terminals $\mathrm{X}_{1}$ and $X_{2}$. The latter was recently used in the oscillator that made 


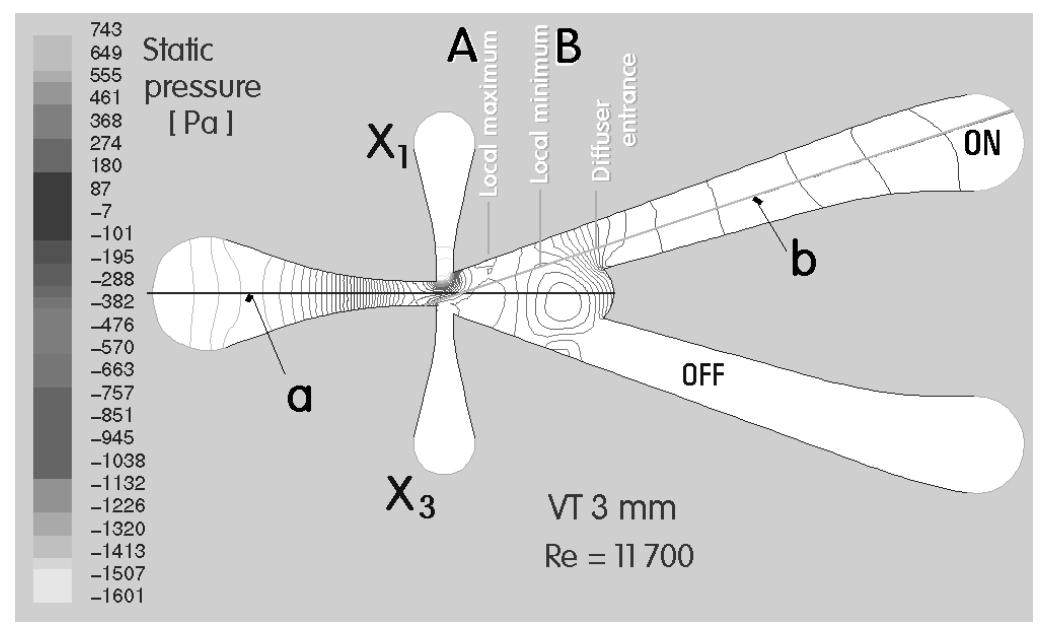

Fig. 5 Pressure field inside a shorter-diffusers version of the amplifier at zero control flows and the jet attached to the $\mathrm{ON}$ side. The very low pressure at the exit from the control terminal $\mathrm{X}_{1}$ is the driving effect for the Spyropoulos-type feedback-loop flow. The dominant depression in the interaction cavity is caused by the stabilising feedback vortex M shown in Fig. 4.

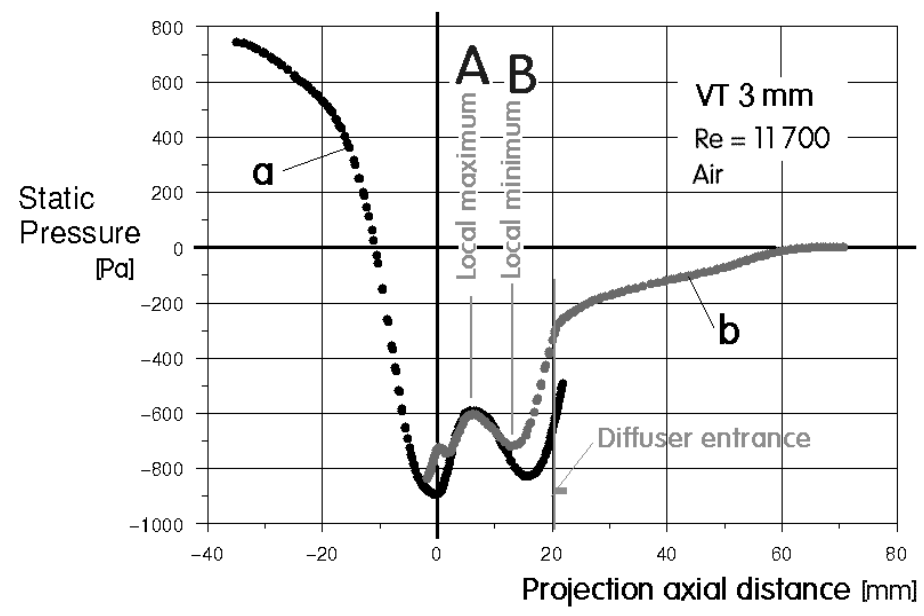

Fig. 6 Rather more complex than expected variations of pressure along the main flowpath in the amplifier from Fig. 5. Note that a substantial proportion (in fact more than $50 \%$ ) of the pressure recovery takes place before the flow enters the $\mathrm{ON}$ diffuser.

possible high heat transfer rates (Tesar, 2009b), or generation the synthetic (or hybridsynthetic [Tesar et al. 2006, Tesar 2007]) jets for control of flow past bodies (Gregory et al 2009). In both feedback layouts, it is usual to leave the shifting of phase in the loop to the velocity of fluid flow in the loop - requiring no special devices (unless it is requested to have the oscillation frequency very low, which is not the case here). The frequency of the oscillation is simply adjusted by varying the length of the feedback loop channel. 
While the actual jet deflection mechanism takes place in the rather small central interaction cavity, the largest proportion of the jet-deflection amplifier occupy auxiliary parts: nozzles and diffusers. In a nozzle (Tesar, 2008), the cross-sectional area decreases in the streamwise direction and for mass conservation (because fluid density does not change significantly) the fluid is accelerated. It is the resultant high velocity that actually makes the jet sensitive to the transversal deflecting action of the control nozzles. On the opposing sides of the interaction cavity there are two walls to either one of which the jet attaches by the Coanda effect.

The attachment precludes the jet deflection from being continuous. Instead, the jet can only switch very fast between the two stable attachment states. This results in the output flow having the character of pulse train rather than harmonic oscillation. In fact, in the discussed amplifier layout, the deflected jet state is stabilised not only by the attachment, but also by the internal stabilising feedback loop in the form of the trapped vortex flow ( $M$ in Fig. 4) imparted by the biscuspid shape of the splitter nose (Figs. 3 to 5). The cusps define the locations in which the jet is captured by a collector (Tesar and Bandulasena, 2010) and led from there into the output terminal.

A rough rule valid for hydromechanics maintains the magnitude of dissipation losses is proportional to the square of velocity. To keep losses low, it is advisable to shape the channels downstream from the collectors as diffusers - i.e. with gradually increasing cross sections in the streamwise direction. It has been always maintained that the good quality of the diffusers - their recovery action converting the kinetic energy of the fluid into the pressure rise - decides over the overall efficiency of the amplifier. It was only recently discovered [Tesar 2009a, Tesar and Bandulasena, 2010] that substantial influence on the pressure recovery (the rise of pressure form the minimum $A$ in Fig. 6 to the zero level in the ON output) have the vortical structures, Fig. 4, trapped inside the amplifier interaction cavity.
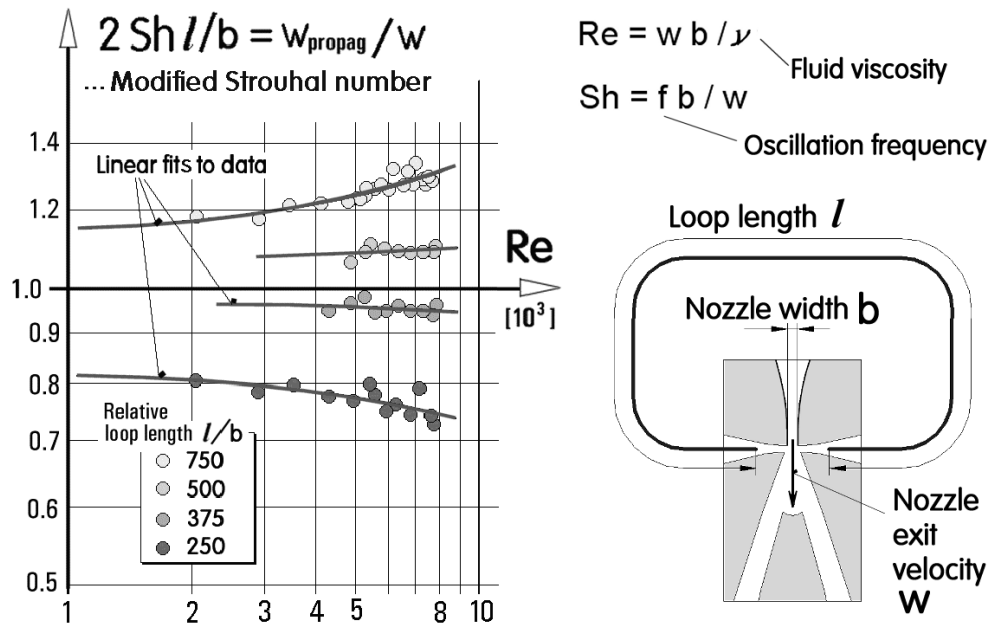

Fig. 7 Dependence of modified Strouhal number Sh on Reynolds number Re obtained for the oscillator with Spyropoulos feedback. As the relative loop length $l / b$ becomes shorter, the decrease of the ratio of the propagation velocity $w_{\text {propag. }}$ in the loop to the main nozzle exit velocity $w$ is explained by the increasing influence of the finite jet switching time in the amplifier. 
Recent investigations have also discovered several interesting facts about the role of the feedback channel and the influence of its length $l$. A general rule for aerodynamic, nomoving-part oscillation in fluids maintains they are characterised by constant value of Strouhal number, in jet flow evaluated from the nozzle exit velocity, oscillation frequency and the nozzle exit width b. In fluidic oscillators, unless they are governed by acoustic waveguide effect of the loop, it is the modified Strouhal number, Fig. 7, which may be said to be constant (Tesar et al. 2007). This number is actually a ratio of the feedback signal propagation velocity in the loop $w_{\text {propag. }}$ to the main nozzle exit velocity $w-$ and fig. 7 demonstrates the two velocities are practically the same - except that there is a small dependence on the channel length due to the finite jet switching time in the amplifier, which the modified Strouhal number does not take into account.

\section{\$2.2 Pilot scale bioreactor design}

Growing microalgae in photobioreactors has been a well established process and exercised all over the world. Kunjapur and Eldridge (2010) review the various designs of enclosed photobioreactors and open systems. However, algae growth is limited by many factors determined by the design of the bioreactor. By incorporating microbubbles that come at a cheaper price, we not only improved transport processes that facilitates good growth rates but also solved issues associated with growth inhibition. A constant gas flow can be oscillated at a preferred frequency via a fluidic oscillator that has no moving parts and requires no external energy input. The frequency of the outlet streams is controlled by changing the length of the feedback loop. Ceramic diffusers fed through a fluidic oscillator generate bubble of approximately $300 \mu \mathrm{m}$ in diameter and draws less energy compared to a conventional aeration system.

Microbubbles have a much larger surface to volume ratio compared to that of larger bubbles produced by conventional aeration systems. This feature can exploited to enhance mass transfer between gas and liquid that are directly in contact within a photobioreactor. In our design, microbubbles are expected to transfer $\mathrm{CO}_{2}$ required for photosynthesis efficiently while stripping the oxygen produced by algae as a by-product. By providing acres of surface area packed into a smaller volume, mass transfer limitation due to finite interfacial area is avoided. This two-way mass transfer process is crucial for achieving higher growth rates at high algae densities.

The next major limitation for growing algae is providing sufficient light for photosynthesis. In our trails, we have seen a direct correlation between algae growth and light intensity. At high algae densities, light penetration becomes weaker; hence leaving algae away from walls and top surface in the dark. To alleviate this problem, we have incorporated an air lift loop system to bring algae to shining surfaces more frequently. As shown in figure 8, the bubbling area is separated from the rest of the volume by using rectangular baffles. Microbubbles rising within the baffled regions drag liquid and algae to the top surface and release them as bubbles burst at the top surface. These regions where bubbles rise to the top surface are called riser regions. Rest of the regions are called downcomer regions, where the fluid and algae 
travels down after spreading sideways at the top surface. These downward streams rejoin the rising streams at the bottom of the tank through the space between baffles and diffusers. This mixing and recirculation not only bring algae to illuminated surfaces, but keeps algae well suspended in the reactor. Well mixed algae have shown lower death rates due to proximity to nutrients, light and gas exchange.

The bioreactor was designed as a closed system to fulfil two requirements. Firstly, the exhaust gas produced by the power plant contains many harmful gases such as $\mathrm{CO}, \mathrm{SOx}$ and NOx; hence should be released to environment at a high altitude using a stack. An open system does not provide means to fulfil this requirement. The other requirement is to avoid contamination at testing stage. Even though we selected a tougher algae strain, we do not want competition for nutrients due to other air born microorganisms. By designing a closed system, we can be certain that our measurements such as chlorophyll content and dry weight are purely from the strain we introduced initially. The gas outlet at the top of the bioreactor was connected to the stack, which is under slightly negative pressure, to exhaust used gases safely.

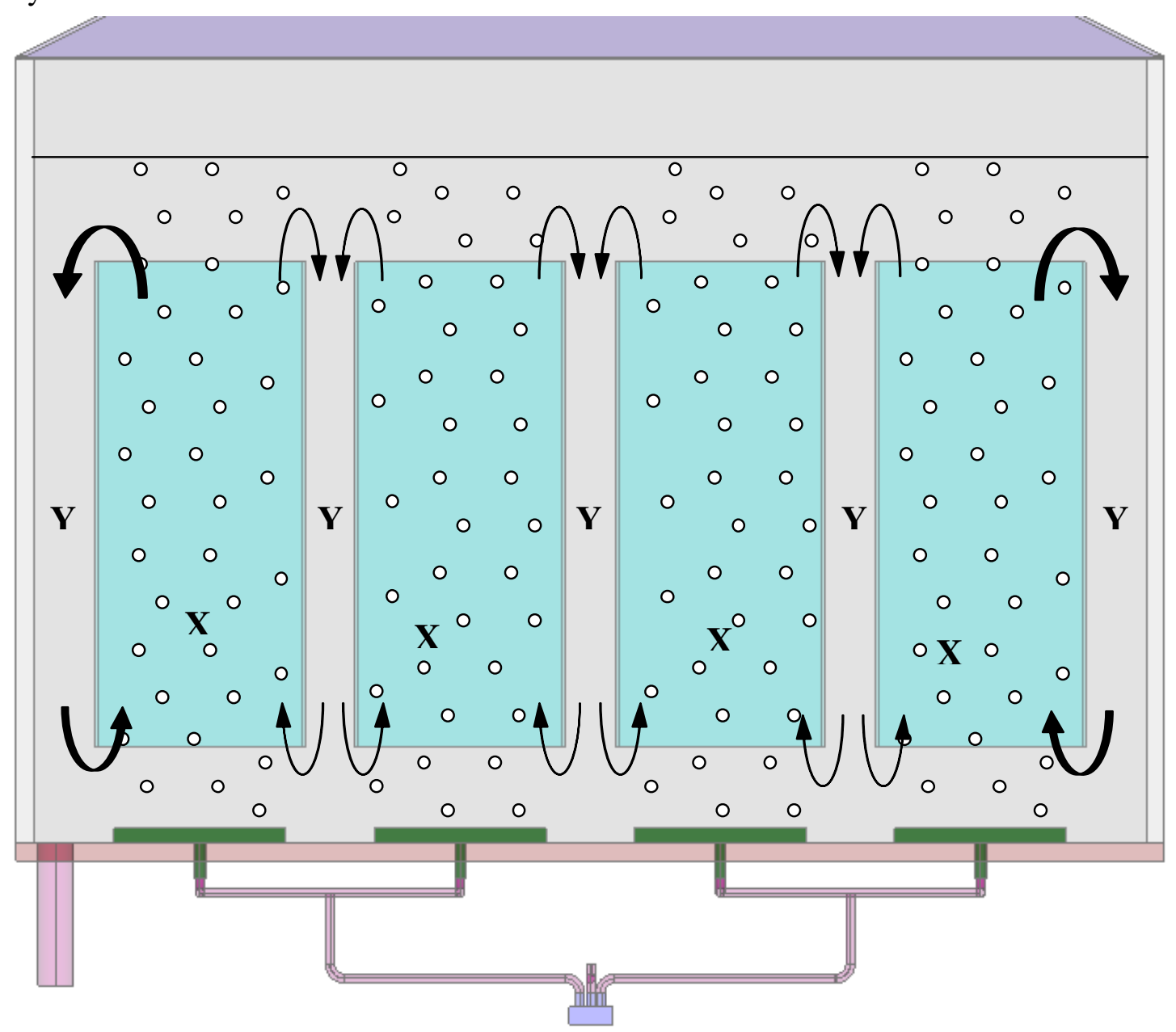

Figure 8. Air lift loop design incorporated to promote recirculation and mixing. Riser regions and downcomer regions are marked with letters $\mathrm{X}$ and $\mathrm{Y}$ respectively. Diffusers are fed through a fluidic oscillator to produce approximately $300 \mu \mathrm{m}$ bubbles. 


\section{§2.3 Energy Efficient Microbubble Generation by Fluidic Oscillation}

Zimmerman et al $(2008,2009)$ report on an energy efficient mechanism for the generation of microbubbles on the size of the pore used to disperse the bubble by using a fluidic oscillator, such as that designed in $\$ 2.1$. If the frequency of the oscillation is sufficiently high and the distribution of the antechamber before the bank of pores gives a good distribution, the bubble cloud generated is of the scale of the pore. Surface wetting properties have an influence on the size of the generated bubbles. In general, hydrophilic surfaces have a thin water film between the bubble and the pore material, and hence the hydrophobic gas (say air) does not adhere to the solid surfaces. The bubbles are observed to "shoot" out like bullets from the pores, rather than the conventional slow pushing out from the pore as under steady flow. The air pulses control the size of the bubbles.

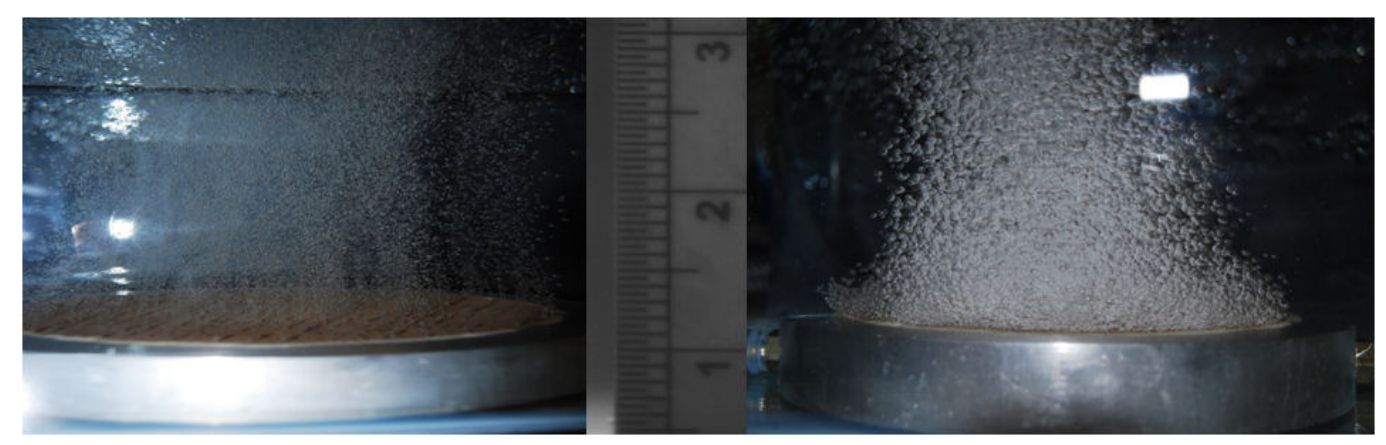

Figure 9. Comparison of fluidic oscillator driven microbubble generation. The right side of the figure shows the result of steady flow through a $15 \mathrm{~cm}$ diameter microporous diffuser with 20 micron size pores. The bubbles are approximately 500microns in size from a combination of formation that is much larger than the pore, and from coalescence. The left hand side shows a closeup of the same diffuser with a fast oscillation $(\sim 90 \mathrm{~Hz})$ and flow rate tuned to the Stokes rise velocity. The resultant bubble cloud is non-coalescent, nearly uniformly dispersed, and with size tuneable from 20-100 microns and practically monodisperse at low injection rates. At the high injection rates used here, coalescence results in a distribution around 300 microns. For some applications, energy efficiency is desired and the high transfer rates at low volumetric flow rates are highly desirable. For high throughput dissolution applications (such as $\mathrm{CO}_{2}$ scrubbing done here), high flow rates and approximately $40 \%$ gas phase hold up are necessary, but result in somewhat larger flow rates.

The limitation in the length of the pulse is a straightforward application of wave dynamics theory. The speed of the carrier wave is the linear velocity of the fluid, hence division by the frequency of oscillation gives the "wavelength" of the pulse or half-width of the solitary wave of momentum (see Zimmerman and Rees, 2004). Clearly, the linear flow rate must be as small as possible and the frequency as large as possible to miniaturize microbubbles to nanobubbles from this approach. As the oscillator used to create the microbubbles in Figure 9 achieves $1-100 \mathrm{~Hz}$ fundamental frequencies, it is estimated that higher harmonics of the oscillation in the fluidic oscillator chamber are responsible for the smallest bubbles that are 
generated. It should be noted that oscillatory flow is inherently different from classical calculations of droplet or bubble mass based on Tate's Law (see Adamson, 1990):

$$
W=2 \pi r \gamma
$$

Where the weight $\mathrm{W}$ of the droplet or bubble is calculable directly by the pore size and surface tension. As the density of gas is so small, Tate's Law guarantees a much larger diameter bubble than the pore radius $r$ unless surface tension $\gamma$ is vanishingly small. Of course a predominant feature of water is its large surface tension. Thus, wetting effects are intrinsically different in a fluidic oscillator induced microbubble than in a conventional steady flow bubble generator.

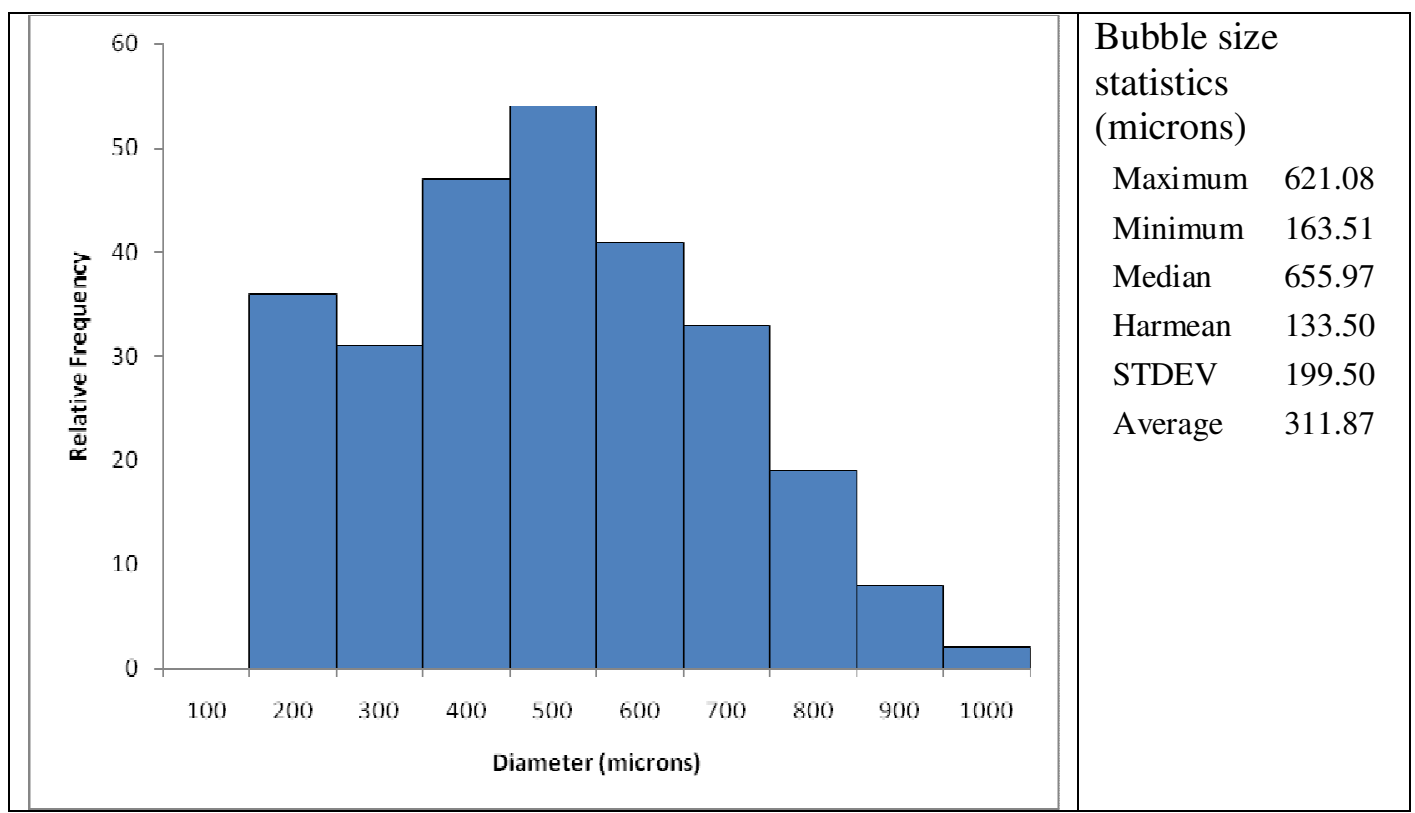

Figure 10 Bubble size distribution (unnormalized count) from a microporous ceramic diffuser from the 20 micron size pores. Air pressure was 0.5 bar gauge with 80 liters $/ \mathrm{min}$ flow rate through a $24 \mathrm{~cm} \times 24 \mathrm{~cm}$ square diffuser of Figure 9 with the fluidic oscillator design in $\$ 2.1$. ImageJ software was applied to the images of a Photron high speed camera captured at 500 frames/s for the estimation of the size distribution.

\section{§2.4 Microalgae pre-culture}

Dunaliella salina strain 19/30 was obtained from the Culture Centre of Algae and Protozoa (CCAP), Oban, Scotland. The alga was routinely grown as static cultures in $250 \mathrm{ml}$ flasks containing $100 \mathrm{ml}$ of Dunaliella medium (Table 3). The flasks were grown at a light intensity of $25 \mathrm{~W} / \mathrm{m} 2$ with daily manual shaking. After two weeks growth 20 flasks were aseptically combined and the resultant $2 \mathrm{~L}$ of microalgae inoculant from the lab-scale culture were transferred to our 250L-bioreactor (Figure 11, see Zimmerman et al. 2009) which containing 248L culture medium. Gas containing $5 \% \mathrm{CO}_{2}$ and $95 \% \mathrm{~N}_{2}$ was issued from gas cylinder to dose the culture under the flowrate of $1 \mathrm{~L} / \mathrm{min}, 6$ hours per day. After around 2 weeks' culture, these microalgae were harvested into several drums which were then delivered to Scunthorpe site, ready for the field trial. 

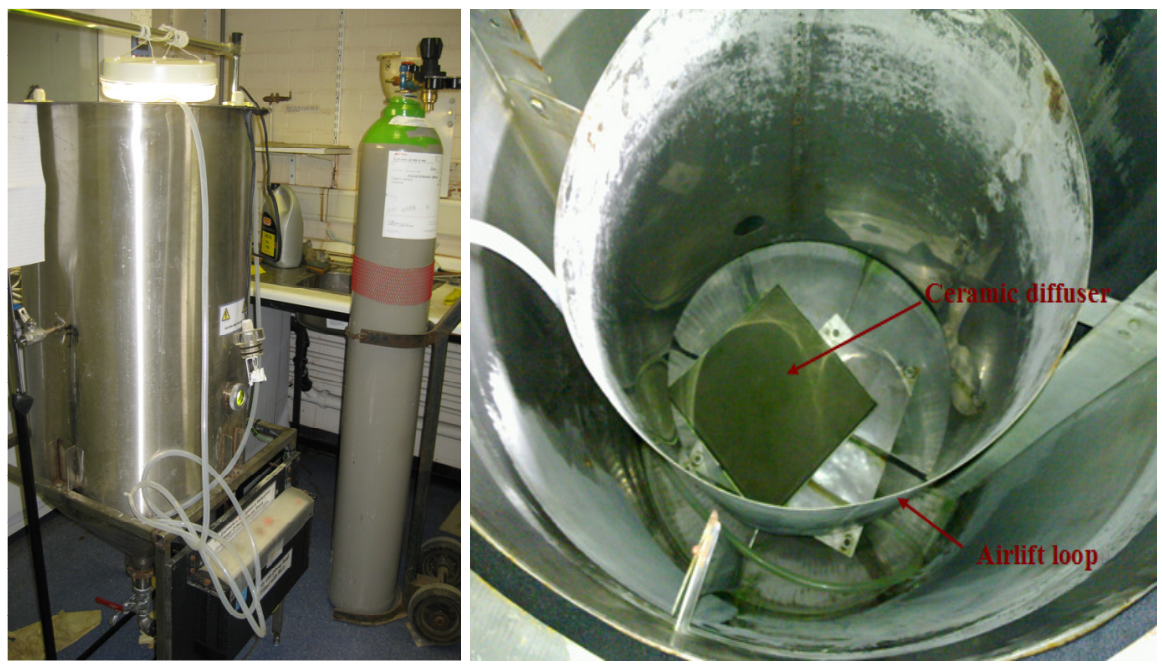

Figure 11 Left: the setup of 250L-bioreactor. Right: the inside configuration of bioreactor. A ceramic diffuser $(20 \mu \mathrm{m}$ in pore size $)$ with the dimensions of $20 \mathrm{~cm} \times 20 \mathrm{~cm} \times 3 \mathrm{~cm}$ was fixed at the bottom. An annular baffle hanged above the diffuser acts as airlift loop, providing a proper mixing feature. The inlet port of each diffuser was connected to the output terminals of non-moving-part oscillator. The supply terminal of oscillator was connected to the gas cylinder. A soft white light source was positioned above the top of the reactor for illumination.

The innoculum was introduced into a culture medium with the constituency of Table 3.

Table 3 Culture medium for pilot scale trials.

\begin{tabular}{|l|l|}
\hline Stock Solution & Conc. needed $(\mathrm{mM} / \mathrm{L})$ \\
\hline $1 \mathrm{M} \mathrm{NaCl}$ & $1.5 \mathrm{M} / \mathrm{L}$ \\
\hline $2 \mathrm{M} \mathrm{KCl}$ & 10 \\
\hline $2 \mathrm{M} \mathrm{MgCl}_{2}$ & 12 \\
\hline $1 \mathrm{M} \mathrm{CaCl}_{2}$ & 5 \\
\hline $2.4 \mathrm{M} \mathrm{MgSO}_{4}$ & 24 \\
\hline $4 \mathrm{M} \mathrm{NaNO}_{3}$ & 5 \\
\hline $0.5 \mathrm{M} \mathrm{Na}_{2} \mathrm{SO}_{4}$ & 6 \\
\hline $100 \mathrm{mM} \mathrm{NaH}_{2} \mathrm{PO}_{4}$ & 0.1 \\
\hline $1.5 \mathrm{mM} \mathrm{FeEDTA}$ & 0.0015 \\
\hline Trace elements & $1 \mathrm{ml} / \mathrm{L}$ \\
\hline Solid NaHCO & $1 \mathrm{~g} / \mathrm{L}$ \\
\hline
\end{tabular}




\section{$\S 2.5$ Wet chemistry analysis}

Samples of $200 \mathrm{ml}$ vials of the bioculture laden with $D$. salina were taken from the drain pipe every day after properly mixing. The quantity of algal biomass presented in culture was evaluated by the determinations of chlorophyll content, dry weight and total lipid content.

\section{Chlorophyll content measurement}

$5 \mathrm{ml}$ of microalgae sample was aseptically transferred into a $15 \mathrm{ml}$ Falcon tube, which was then centrifuged at full speed $(3000 \mathrm{~g})$ for 10 minutes. The supernatant was poured off immediately, followed by re-suspending each pellet in $1 \mathrm{ml}$ of distilled water. $4 \mathrm{ml}$ of acetone was then added to each tube and whirlmixed properly. The tube was then centrifuged again at full speed for 5 minutes, until the pellet was completely white. Finally, the optical density of the supernatant was measured at $645 \mathrm{~nm}$ and $663 \mathrm{~nm}$ separately after zeroing the spectrophotometer by acetone. The chlorophyll content was then calculated according to the equation (McKinney, 1941):

$$
\text { Chlorophyll }(\mu \mathrm{g} / \mathrm{ml})=\frac{O D_{645} \times 202+O D_{663} \times 80.2}{2 \times 5}
$$

\section{Dry weight and lipid content measurement}

$4 \times 15 \mathrm{ml}$ of algal samples were centrifuged for 10 minutes at $3000 \mathrm{~g}$. The supernatant was poured off immediately, followed by re-suspending each pellet in $5 \mathrm{ml}$ of distilled water, and then centrifuged again for 5 minutes at $3000 \mathrm{~g}$. Again, each pellet was re-suspended in $5 \mathrm{ml}$ of distilled water, centrifuged for 5 minutes at $3000 \mathrm{~g}$. After discarding supernatant, each pellet was re-suspended in $1 \mathrm{ml}$ of distilled water. Four Eppendorf tubes were labeled and weighed on the fine balance. Then, $1 \mathrm{ml}$ samples were transferred to these four pre-weighed Eppendorf tubes. Four lids cut off from another four Eppendorf tubes, with a hole made in each lid by using a dissecting needle, were put on the four Eppendorf tubes containing samples. These samples were freezed at minus $80^{\circ} \mathrm{C}$ overnight and then lyophilized for 24 48 hours. The Eppendorf tubes were re-weighed to estimate the weight of biomass.

Then, $500 \mu \mathrm{l}$ of methanol/chloroform $(2: 1 \mathrm{v} / \mathrm{v})$ were added into these tubes and sonicated for 1 minute on ice, followed by centrifuging at full speed for 5 minutes and transferring the supernatant (estimate the volume) to a fresh Eppendorf tube. Chloroform and $1 \% \mathrm{NaCl}$ were added into this tube to give 2:2:1 methanol:chloroform:water. The Eppendorfs were centrifuged in microfuge for 2 minutes at full speed, followed by labeling and weighing fresh Eppendorfs and transferring chloroform phase (green phase) into the pre-weighed Eppendorfs. These Eppendorfs were then placed in Fume Cupboard, with tops open to evaporate overnight or until dry. After that, the Eppendorfs were re-weighed and the weight of lipids recovered was calculated.

\section{$\S 2.6$ Gas analysis}

The inlet (exhaust gas source) and outlet gases from the enclosed pilot scale bioreactor (Figure 8) were equipped with state-of-the-art Gasmet FTIR gas analyzers which ran continuously, regardless of whether the bioreactor was switched "on" - receiving gas from 
the steel power plant exhaust gases. This permitted the monitoring of the gas exchange in absence and presence of microbubble dosing.

\section{Results and Discussion}

There are many variables in conducting such a complex experimental programme as this, and controlling for all of them was not possible, so as to test for the individual response to each. Our objectives, however, were to assess whether microbubble mediation of the gas transfer process had the desired effects. Ideally, we would try many different bubble size distributions and volumetric flow rates, but changing the bubble size independently "on the fly" is not possible - it requires the modification of the microporous diffusers. Hence, we were delighted to make several observations from the operation:

- In the regime of volumetric flow rates tried (10-80 liters/min) with a single fluidic oscillator, all of the algae were suspended. None attached to the walls of the bioreactor or the internal baffles. None were trapped in stagnant zones. The "suspension power" was visually sufficient in this range that the bioreactor could have been an estimated 10 -fold taller without any difficulty - the bubbles always have to rise!

- In all our lab scale ALB studies and in both field trials, there was $100 \%$ survival rate. We had expected that some algae would die in stagnant zones, and had even collected samples of algae native to the Scunthorpe plant that might be acclimated to trace impurities in the exhaust gases. One member of the investigatory team was assigned for the purpose of broad spectrum biochemical analysis so that we could learn what might have caused the demise of an expected large fraction of the bioculture - which never occurred. There was no observation of infection either, but that may be a consequence of the salinity $-D$. salina thrives in $1 \mathrm{M}$ salt solution, and nothing much else does, and what other species grow are not particularly harmful to algae or a human biohazard.

- Given that for weekends and a long weekend in both trials, no dosing was done, it was remarkable that the bioculture simply waited for the arrival of fresh $\mathrm{CO}_{2}$ nutrient. The first trial was also very cold, which apparently only lengthened the lag phase of growth.

- In trial 2, as the end approached, the density of wet biomass was so great that the tank was visibly black, yet there was no appreciable impact on growth rates from the optical density potentially blocking the sunlight from the internal algae. This suggests that the suspension as well as the "parading" effect of the airlift loop of algae transported by bubble flocculation resulted in fairly uniform exposure of the algae to the lighted surface.

In this section, we present the results of the analytical chemistry of the samples and the gas monitoring and analysis. 


\section{$\S 3.1$ Wet chemistry analysis}

$200 \mathrm{ml}$ of algal samples were taken per working day after properly mixing by aerating. The quantity of algae presented in culture was evaluated by the determinations of chlorophyll content, dry biomass weight and lipid content.

The differences of conditions between both cultures are listed in Table 4,

Table 4: The differences of culture conditions between trial 1 and trial 2

\begin{tabular}{|c|c|c|c|c|}
\hline Trial & Inoculants status & $\begin{array}{c}\text { Aeration time } \\
\text { \& Flowrate }\end{array}$ & $\begin{array}{l}\text { Culture } \\
\text { days }\end{array}$ & $\begin{array}{c}\text { Culture } \\
\text { temperature }\end{array}$ \\
\hline Trial 1 & $\begin{array}{l}D . S . ; \text { steady phase } \\
\text { higher conc. of } \\
\text { biomass; lower } \\
\text { conc. of chlorophyll } \\
\text { content and total } \\
\text { lipid content }\end{array}$ & $\begin{array}{c}\text { Various, } \\
\text { approximately } \\
\text { equal to } \\
30 \mathrm{~L} / \mathrm{min} \times \\
\text { 3hrs/day }\end{array}$ & 10 days & $\begin{array}{l}\text { During aerating: } 12- \\
\qquad 18^{\circ} \mathrm{C} \\
\text { After aerating: } 1-9^{\circ} \mathrm{C}\end{array}$ \\
\hline Trial 2 & $\begin{array}{l}\text { D.S.; log growth } \\
\text { phase } \\
\text { lower conc. of } \\
\text { biomass; higher } \\
\text { conc. of chlorophyll } \\
\text { content and total } \\
\text { lipid content }\end{array}$ & $\begin{array}{c}40 \mathrm{~L} / \mathrm{min} \times 10- \\
12 \mathrm{hrs} / \text { day }\end{array}$ & 17 days & Constantly $23^{\circ} \mathrm{C}$ \\
\hline
\end{tabular}

\section{Chlorophyll content}

Figure 12 gives the trend of chlorophyll content increase for field trial 1 and trial 2. The lack of data for certain days was due to 'lab limitation' restricted by Corus ltd.

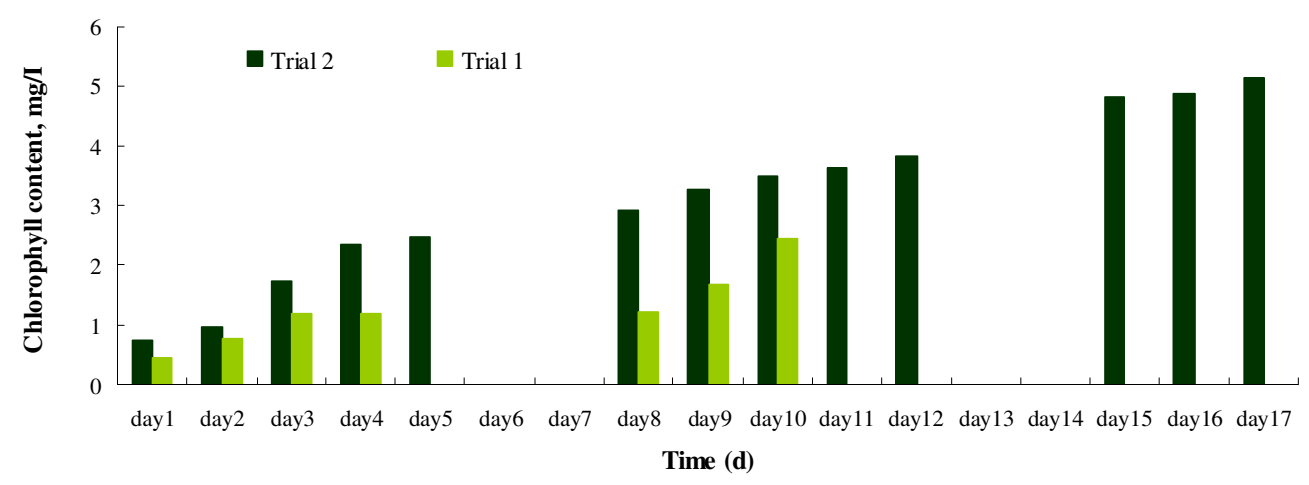

Figure 12: The increase in algal chlorophyll content for trial 1 and trial 2

Generally, for both trials, Dunaliella Salina presented a great adaptability to the flue gas dosed by microbubble generation system. The chlorophyll content increased from initially $0.45 \mathrm{mg} / \mathrm{L}$ to finally $2.44 \mathrm{mg} / \mathrm{L}$ for trial 1 , and for trial 2 , increased from $0.73 \mathrm{mg} / \mathrm{l}$ to 5.14 $\mathrm{mg} / \mathrm{l}$. 
Comparing trial 1 with trial 2 , the chlorophyll content in later was obviously higher than former. As regard to trial 1, the chlorophyll content did not grow substantially until the $8^{\text {th }}$ day. The lag phase, caused by physiological adjustment of algae, took about 7 days which was relatively longer compared with trial 2 . Such delay in lag phase was caused by three major reasons. First, for most of species, the optimal temperature usually ranges from 20 to $27^{\circ} \mathrm{C}$ (Coutteau, 1996), but the culture temperature in trial $1,1-18^{\circ} \mathrm{C}$, were too low to inhibit the algal growth to some extent. Second, the inoculants for trial 1 were getting close to dead phase, the low activities of these inoculants could be another factor delaying the lag phase for a new culture. Third, during the stoppage (day5 - day7), the whole operation system was shut down due to some restrictions in Corus ltd, which means there were no $\mathrm{CO}_{2}$ supplies to our bioreactor. The microbubble generation system supposes to not only transfer $\mathrm{CO}_{2}$ into culture but also strip out $\mathrm{O}_{2}$ from it, but without bubbling, $\mathrm{O}_{2}$ could accumulate in the culture medium, inhibiting the algal growth. Thus, lack of $\mathrm{CO}_{2}$ and the accumulation of $\mathrm{O}_{2}$ limited the growth of algae to most extent during these days. After the lag phase, the amount of chlorophyll content doubled within 3 days, rising from $1.20 \mathrm{mg} / \mathrm{L}$ to $2.44 \mathrm{mg} / \mathrm{L}$, and a further growth was expected to be observed if the culture continuous.

For trial 2, with a better temperature condition and more active inoculants, the lag phase was shortened to 1-2 days and chlorophyll content increased dramatically, rising from $0.73 \mathrm{mg} / \mathrm{L}$ to $5.14 \mathrm{mg} / \mathrm{L}$ within 17 days.

\section{Dry biomass and total lipid content}

The algal dry weight for both trials is plotted in Figure 13, with the increase rate of dry weight shown in Figure 14. In general, the trends of dry biomass increase almost correspond with the chlorophyll content increase. Since the dry biomass of inoculants for trial 1 are far more higher than trial 2, it maintained higher in trial 1, while in terms of dry biomass growth rate, the situation reverse. The algae have a higher growth rate in biomass in trial 2 throughout the culture period.

For trial 1 , the algal dry biomass rise from $0.125 \mathrm{~g} / \mathrm{L}$ to $0.35 \mathrm{~g} / \mathrm{L}$ within 10 days, almost doubled. A slow growth phase was also observed in the first 8 days, followed with a logarithmic growth phase. For trial 2 , initially, the algal dry biomass was only $0.0067 \mathrm{~g} / \mathrm{L}$, but after 17 days' culture it went up to $0.24 \mathrm{~g} / \mathrm{L}$, increased by more than 35 folds.

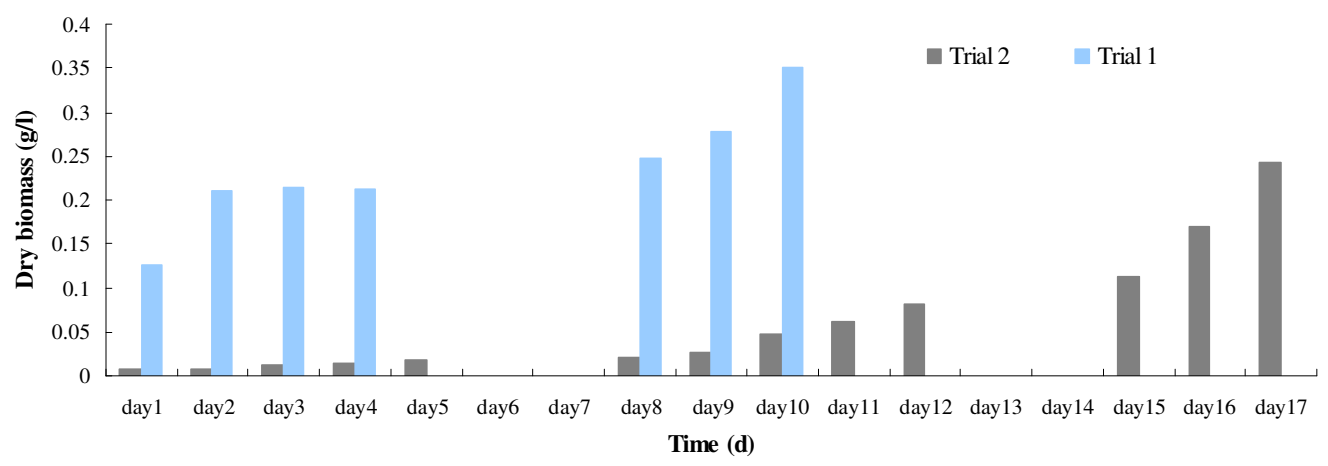

Figure 13: The increase in concentrations of algal dry weight for trial 1 and trial 2 


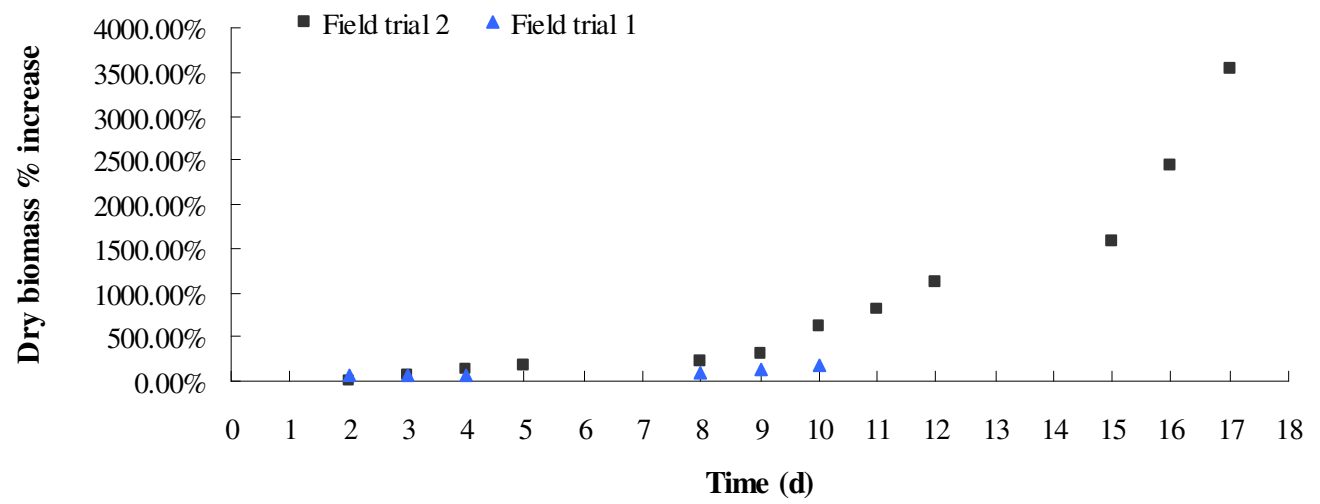

Figure 14: The percentage increase in algal dry biomass for trial 1 and trial 2

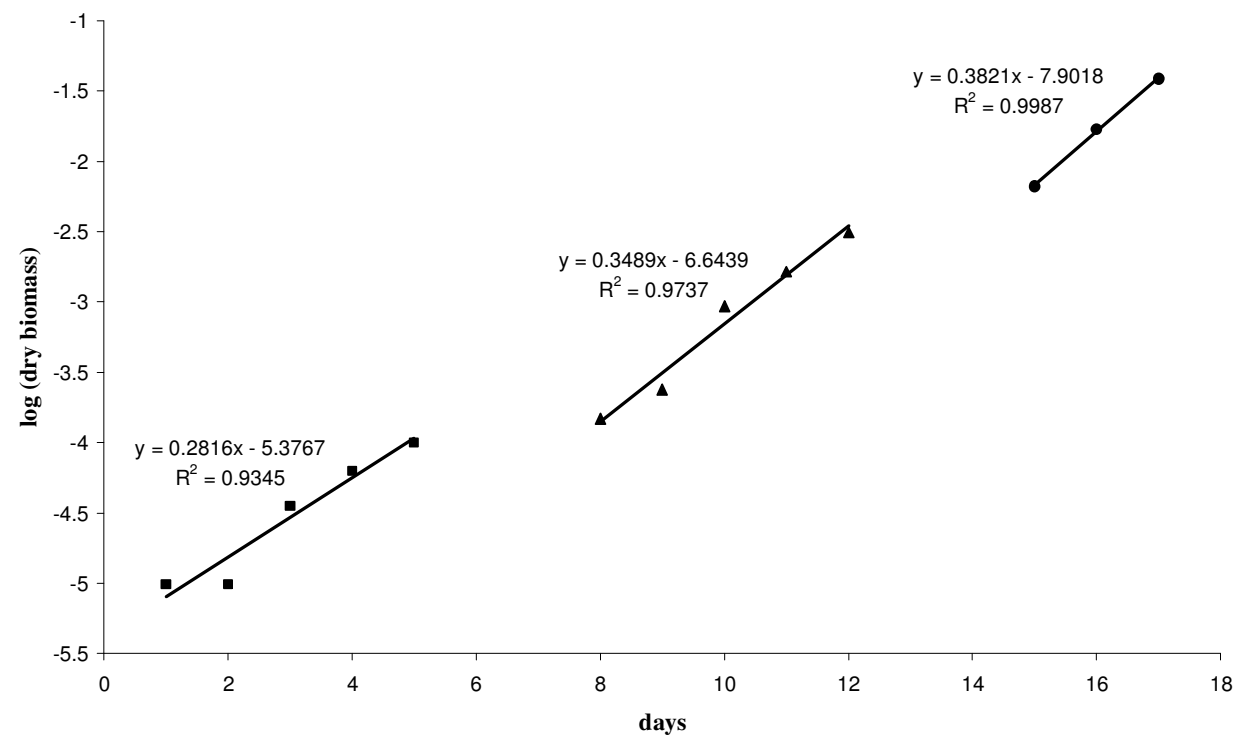

Figure 15: Exponential growth curve fits to the each of the three weekly periods of Trial 2. The doubling times are inferred as week $1=2.5$ days, week $2=2.0$ days, week $3=1.8$ days.

Figure 15 represents the doubling time for the growth curve in Trial 2. Clearly, each week the doubling time was decreasing, showing an acceleration of the exponential growth rate. Such behavior is inconsistent with oxygen inhibition or indeed any nutrient limitation.

The total lipid was extracted from dry biomass by methanol/chloroform. The results are shown in Figure 16. As can be seen, the concentration of total lipid (total lipid content per dry weight, $\mathrm{g} / \mathrm{g}$ ) for trial 2 , ranging from $31 \%$ to $75 \%$, are generally greater than the one in trial 1 , which was in the range of 9-30\% . For both trials, the concentration of total lipid content presented a trend of decline, which indicates during the culture the increase in biomass exceed the increase in total lipid content existing in algal cells. 


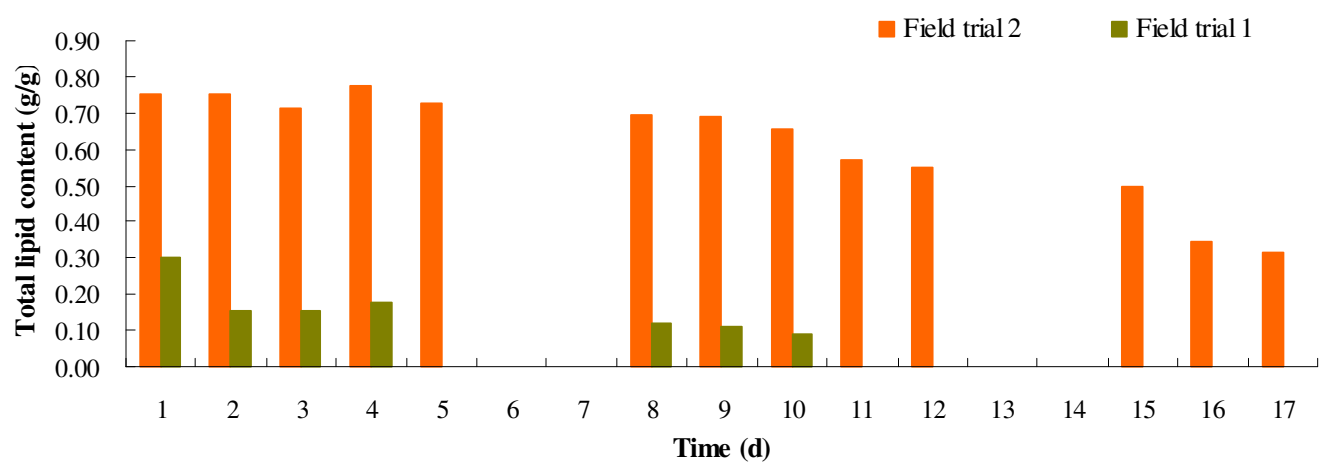

Figure 16: The changes in the total lipid content per cell weight $(\mathrm{g} / \mathrm{g})$ for trial 1 and trial 2

Consider the results of total lipid content along with dry biomass, it turns out that for trial 1 , the culture achieved a higher concentration of biomass while lower concentration of total lipid content. Inversely, for trial 2, a lower biomass concentration but higher total lipid concentration of algal cells was observed. It seems to be a dilemma to say which trial performs better. Actually, in terms of bio-energy (e.g. biodiesel), either biomass enhancement or total lipid growth is important as the final output of the amount of total lipid depends on the product of both. Therefore, the concentration of total lipid content in the entire bioreactor $(\mathrm{g} / \mathrm{L})$ was calculated by multiplying the total lipid content per cell weight $(\mathrm{g} / \mathrm{g})$ by the concentration of dry biomass $(\mathrm{g} / \mathrm{L})$, shown in Figure 16.

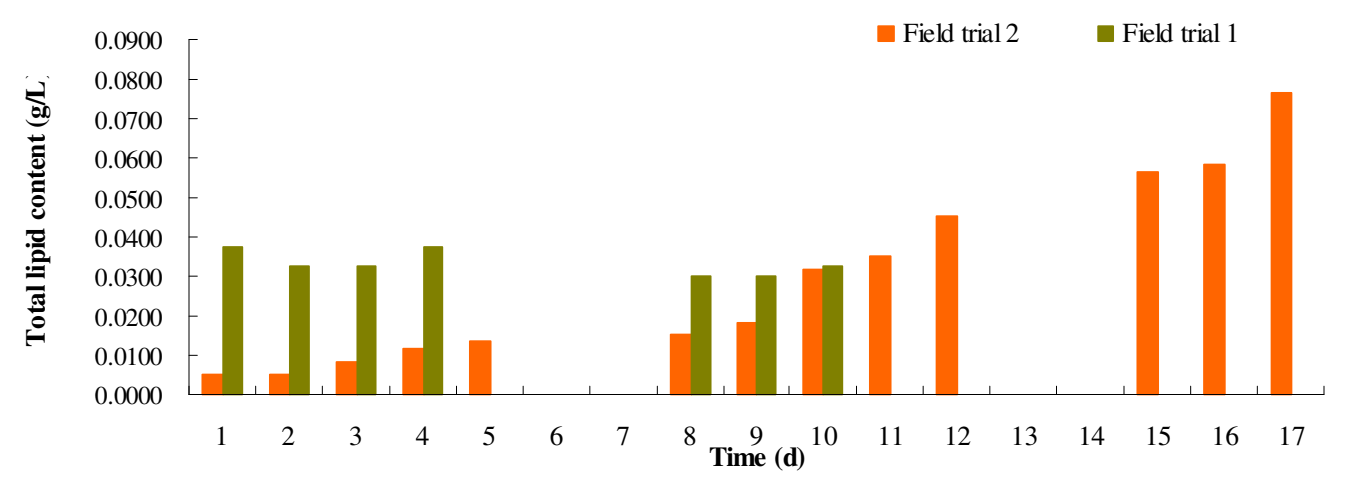

Figure 17: The changes in total lipid content per culture volume (g/l) for trial 1 and trial 2

As can be seen from Figure 17, for trial 1, the total lipid content per culture volume presented a slightly fluctuation, but generally maintained at $0.03 \mathrm{~g} / \mathrm{L}$. For trial 2 , the amount of total lipid increased from $0.005 \mathrm{~g} / \mathrm{L}$ to $0.07 \mathrm{~g} / \mathrm{L}$. Obviously, in terms of biodiesel production, trial 2 seems more favorable, and in such 2200L-culture, the total amount of total lipid content achieved up to $154 \mathrm{~g}$.

\section{$\S 3.2$ Gas monitoring and analysis}

For both trials, a portable Gasmet FTIR was used for monitoring flue gases entering and leaving the bioreactor. Gasmet FTIR Gas analyser represents most advanced measurement technology available for continuous gas analysis. Real time data were recorded directly on a laptop. The analyser can measure up to 50 gases simultaneously. The samples were taken from inlet and out of the bioreactor through a heated line and heated pump. Concentrations of $\mathrm{CO}_{2}$ and $\mathrm{O}_{2}$ in the inlet and out of the bioreactor were monitored $24 \mathrm{~h}$ over the period of both 
trials. Figure 18 shows an example of a day results. In addition the bioreactor temperature was monitored during the trials.

5th of May 2010

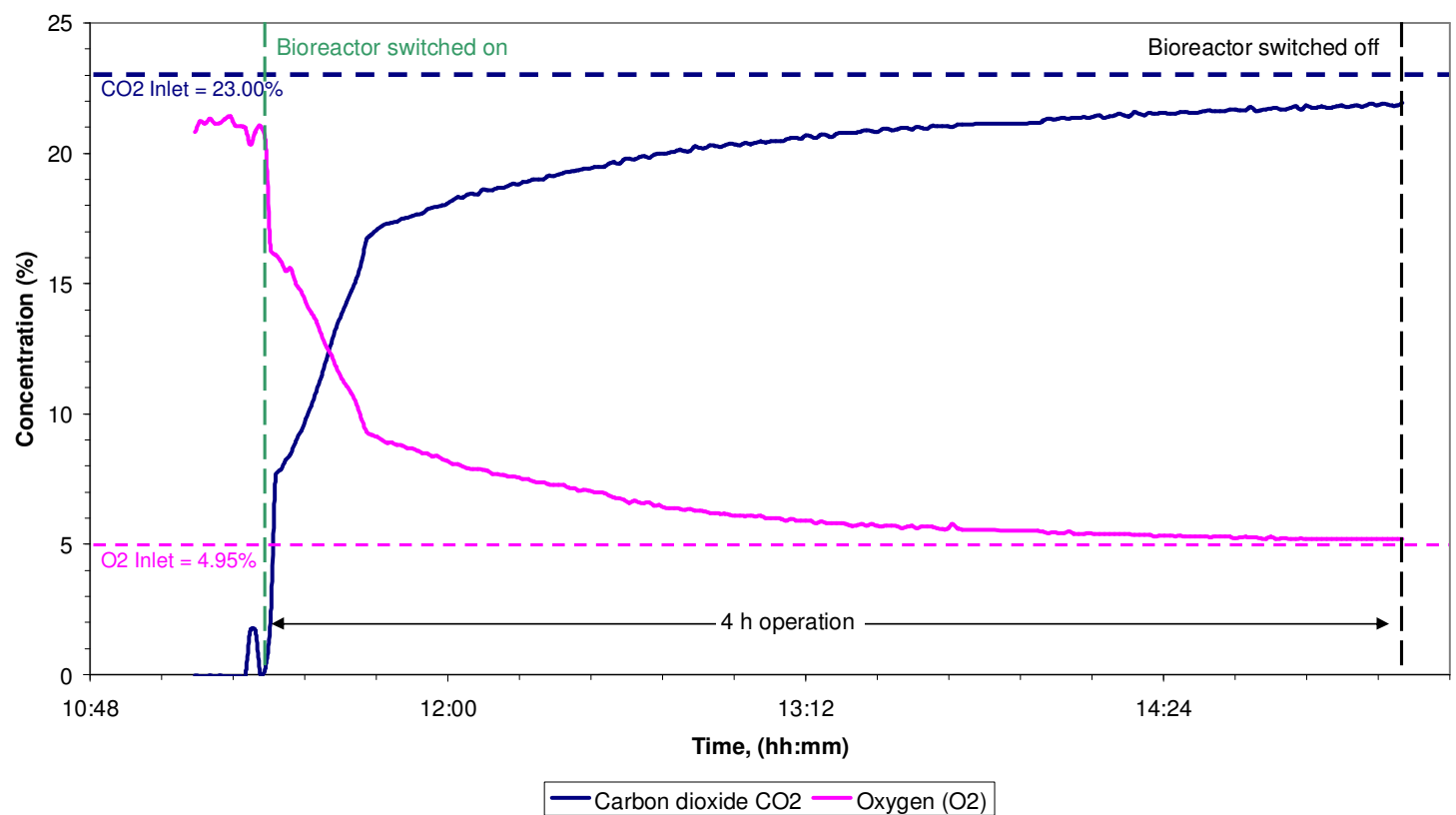

Figure 19: Outlet gas analysis from the bioreactor on 5 May 2010. The exhaust gas had a fairly steady $23 \% \mathrm{CO}_{2}$ and $5 \% \mathrm{O}_{2}$ content. This study was to test the responsiveness of the bioreactor gas exchange to the transients of daily start up of the compressor with a well established bioculture. On start up, within a few minutes, $\mathrm{O}_{2}$ drops to the exhaust gas content, at $80 \mathrm{liter} / \mathrm{min}$, demonstrating complete stripping of the $\mathrm{O}_{2}$ to the level of the stripping gas. On shutdown, after about half an hour, the $\mathrm{CO}_{2}$ still has not risen to the level in the dosing gas, indicating that the $\mathrm{CO}_{2}$ has been taken up by the bioculture. This demonstrates that the bioculture is not mass transfer limited.

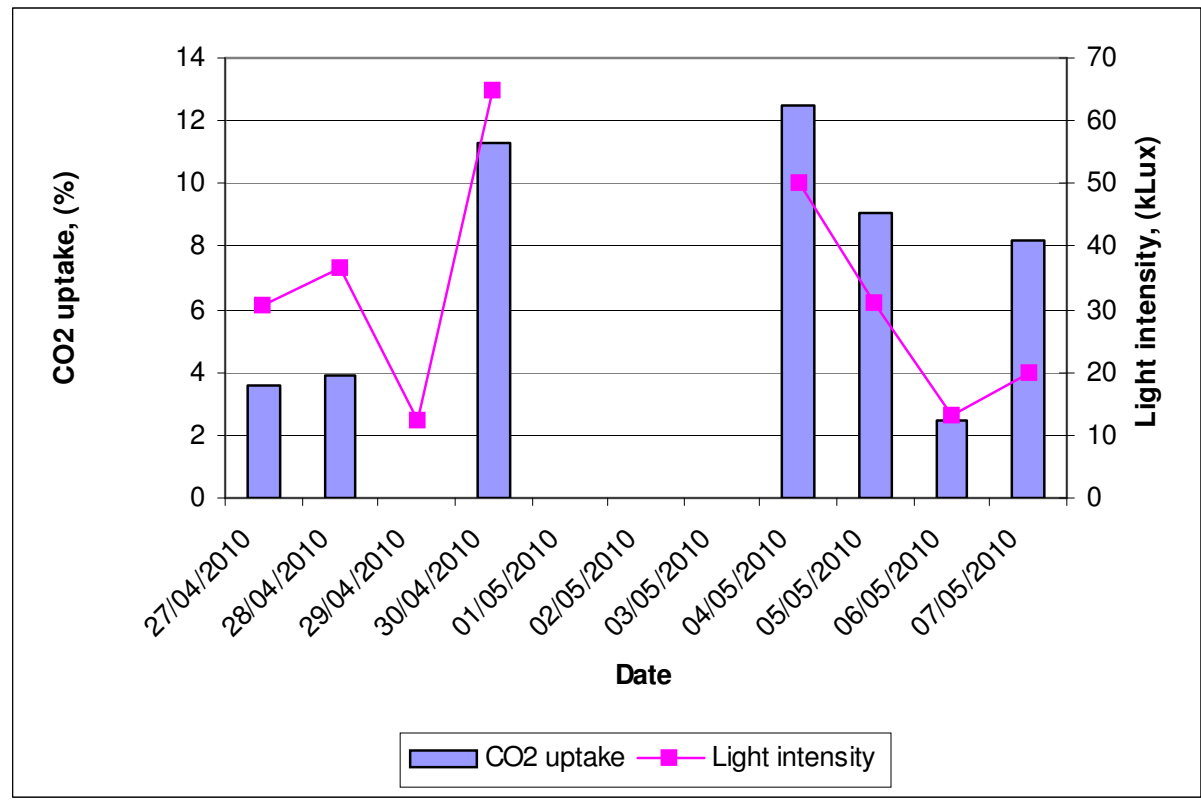

Figure 19: The sunlight intensity was quite variable in Trial 1. Daily $\mathrm{CO}_{2}$ uptake clearly is correlated directly with the average daily light intensity. There was no correlation with either bioreactor temperature (uncontrolled) or volumetric flow rate (controlled), which were both variable daily. 


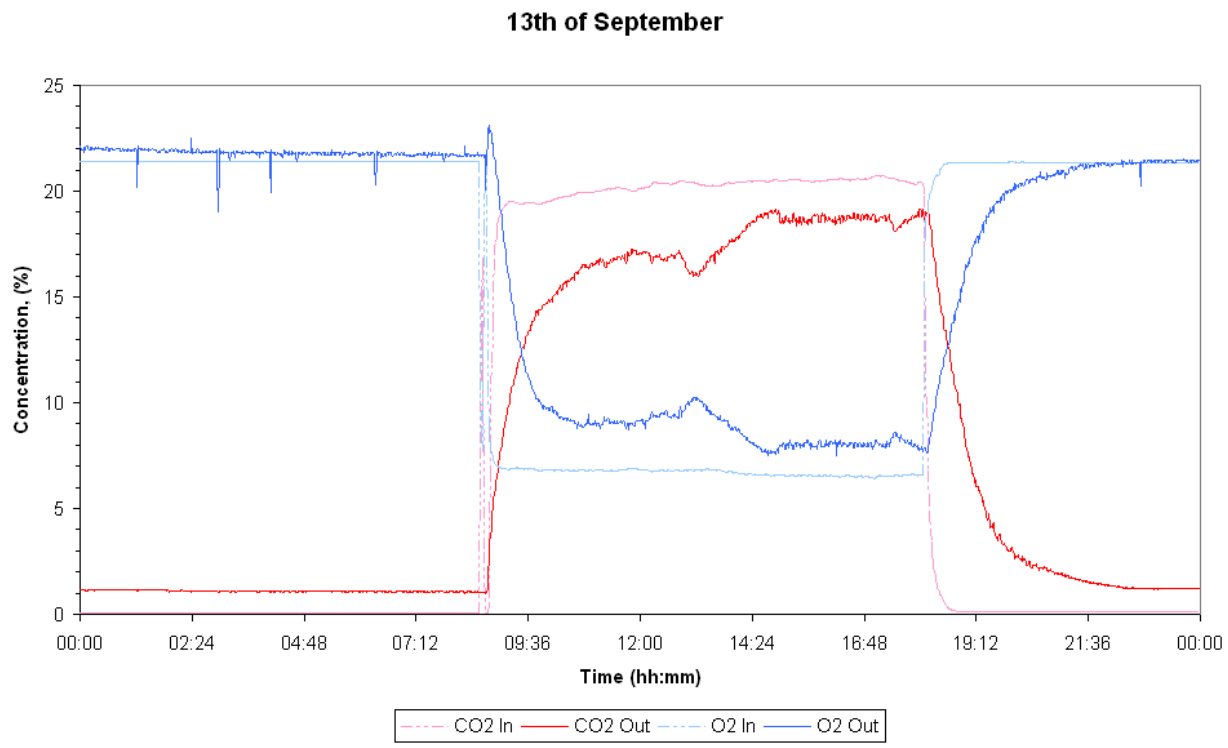

Figure 20: FTIR gas analysis of bioreactor inlet and outlet $\mathrm{CO}_{2}$ and $\mathrm{O}_{2}$ concentrations on 13 September 2010 during Trial 2. There are clearly three periods (i) before the compressor is turned on, with practically no difference between inlet and outlet, as they are both measuring the conditions in the bioreactor from opposite sides; (ii) during operation of the compressor, when the difference between $\mathrm{O}_{2}$ inlet and outlet shows the $\mathrm{O}_{2}$ stripping rate, and between $\mathrm{CO}_{2}$ inlet and outlet show the $\mathrm{CO}_{2}$ uptake rate. The outlet $\mathrm{CO}_{2}$ and $\mathrm{O}_{2}$ concentration profiles are anti-correlated, again demonstrating that the bioreactor is not mass transfer limited. (iii) post-compressor operation, when the bioreactor $\mathrm{O}_{2}$ content returns to the ambient and $\mathrm{CO}_{2}$ is dissipated to the atmosphere and taken up by the culture.

Figure 19 shows that there is a strong correlation between average daily sunlight and daily $\mathrm{CO}_{2}$ uptake in Trial 1. There was no correlation with either bioreactor temperature (uncontrolled) nor with variable flow rates changed daily, varied between 10 and 80 liter/min. Along with the strong correlation between outlet $\mathrm{O}_{2}$ and $\mathrm{CO}_{2}$ profiles in Figure 20, it is clear that all $\mathrm{O}_{2}$ is being effectively stripped, $\mathrm{CO}_{2}$ is dosed sufficiently fast that its rated is metabolically limited, and the whole reactor operation is not mass transfer limited.

Table 5 shows summary of the results for both trials. In the first trial, average temperature of the bioreactor was $16{ }^{\circ} \mathrm{C}$ with overall efficiency of $7 \%$. In the second trial, bioreactor temperature was controlled with average temperature of $22{ }^{\circ} \mathrm{C}$ with the overall efficiency of the bioreactor reaching $14 \%$. The maximum $\mathrm{CO}_{2}$ uptake rate in the second trial reached to $226.4 \mathrm{~g} / \mathrm{hr}$ compared to $92.7 \mathrm{~g} / \mathrm{hr}$ in the first trial. The efficiency of the second trial improved due to better control of the bioreactor temperature. In overall, in this work, $\mathrm{CO}_{2}$ sequestration rate improved compared to works done by others and the overall efficiency of the microbubble bioreactor is in good agreement with the past works. Yun Y-S et al. (1997) successfully sequestrated $0.624 \mathrm{~g} \mathrm{CO}_{2}$ per litre per day $(0.026 \mathrm{~g} / \mathrm{l} / \mathrm{hr})$ compared to this work $(0.1 \mathrm{~g} / \mathrm{l} / \mathrm{hr})$. Doucha (2005) also reported 10 to $50 \%$ reduction in $\mathrm{CO}_{2}$ using Chlorella. The highest fixation rate has been reported by Morais and Costa (2007) using Spirulina (53.29\% for $6 \% \mathrm{v} / \mathrm{v} \mathrm{CO}_{2}$. However, most of the past works showed that the efficiency decreased with increasing $\mathrm{CO}_{2}$ concentration Brennan et al. (2010). With $\mathrm{CO}_{2}$ concentrations over 20\% entering the bioreactor in this work, $14 \%$ efficiency is a substantial reduction. 
Table 5 Integrated $\mathrm{CO}_{2}$ uptake (only during compressor operation) and average bioreactor temperature throughout each trial.

\begin{tabular}{|l|l|c|c|c|c|}
\hline Trial No. & Microalgae & $\mathrm{T}\left({ }^{\circ} \mathrm{C}\right)$ & $\mathrm{CO}_{2}(\%)$ & $\begin{array}{c}\text { Max } \mathrm{CO}_{2} \\
\text { uptake, }(\mathrm{g} / \mathrm{hr})\end{array}$ & $\begin{array}{c}\text { Overall } \\
\text { efficiency, } \\
(\%)\end{array}$ \\
\hline 1 & $\begin{array}{l}\text { Dunaliella } \\
\text { salina }\end{array}$ & 16 & 23 & 92.7 & 7 \\
\hline 2 & $\begin{array}{l}\text { Dunaliella } \\
\text { salina }\end{array}$ & 22 & 20 & 226.4 & 14 \\
\hline
\end{tabular}

\section{$\S 3.3$ Discussion}

In the prologue to this section, several positive observations were made about the viability of the microalgae bioculture in the pilot scale ALB. After the presentation of the wet chemistry analysis and the gas analysis, it is clear that in both trials, only steady growth was eventually observed. In the first trial, due to the low temperature of the bioreactor, it could be argued that the metabolism was slowed, and hence the bioculture never reached a plateau from either oxygen inhibition, nutrient depletion, or build up of waste bioproducts of extracellular metabolites in the liquor. Trial 2 was prepared to alleviate the concern that the metabolism was slowed due to low temperature or due to lack of $\mathrm{CO}_{2}$ nutrient availability, by providing heating to control the temperature closer to the target range, and by dosing for much longer. Given that trial 2 only showed steady growth of chlorophyll, it is reasonable to assume it was never stressed for lack of sunlight. Given that trial two showed accelerating exponential growth (with decreasing doubling times), there is no evidence that conducting the trial at saturated dissolved $\mathrm{CO}_{2}$ (we used a buffer solution to control for mild $\mathrm{pH}$ variation) leads to any detriment in biomass growth.

The evidence argues strongly for the conclusion that the bioculture is not oxygen inhibited nor mass transfer limited during microbubble dosing due to the following supporting facts:

- During microbubble dosing operations, $\mathrm{CO}_{2}$ was consistently delivered faster than the uptake, with extremes of uptake at $4 \%$ and $34 \%$, and an average of $14 \%$. Thus, the oxygen poor stack gas served largely to strip dissolved $\mathrm{O}_{2}$, to the equilibrium level in contact with $5 \%$ gas composition in the microbubbles. The dosing of $\mathrm{CO}_{2}$ and the stripping of $\mathrm{O}_{2}$ was sufficiently fast that $\mathrm{CO}_{2}$ was always in excess (saturated) in the liquid phase and $\mathrm{O}_{2}$ was removed as fast as produced.

- $\mathrm{CO}_{2}$ and $\mathrm{O}_{2}$ profiles were anti-correlated to a high degree by inspection. If the system were mass transfer limited, fluctuations in $\mathrm{CO}_{2}$ uptake would not be mirrored by fluctuations in $\mathrm{O}_{2}$ removal.

- No "plateau" was ever observed, and with accelerating exponential growth rate, none was on the horizon. Clearly, for a batch culture, that is unsustainable, as there is no source of phosphates being introduced. Of course, NOx are soluble in aqueous solution, and potentially are serving as an N-source. Remarkably, neither SOx or NOx dissolution had any apparently negative effect on viability of the bioculture nor growth rate. 


\section{Conclusions}

This was a feasibility study to determine the viability of $D$. salina being dosed with steel plant stack gas, combusted from offgases of the steel making process and used in the power plant. Such gases have a high $\mathrm{CO}_{2}$ content and with rapid mass transfer from microbubble mediated, air lift loop induced mixing, and easily result in saturation of the liquid phase. Generally, previous observations have that high dissolved $\mathrm{CO}_{2}$ levels are not conducive to higher algal biomass growth. From this basic objective, the pilot trials were successful as both showed $100 \%$ survivability.

The trials had a second, more fundamental objective, which was to test the hypothesis that microbubble mediation strips out the $\mathrm{O}_{2}$ and thus removes the inhibition to growing to higher density and with faster growth rates. Gas monitoring and analysis demonstrate that $\mathrm{O}_{2}$ was stripped to the equilibrium level to that of the stripping exhaust gas. Steady chlorophyll growth, and accelerating exponential growth of biomass, are consistent with stripping the $\mathrm{O}_{2}$ having removed the inhibitory effect.

The airlift loop effect could also be credited with a very useful suspension effect (at no extra cost given that it is a by-product of the microbubble dosing) which results in the parading of the microalgae, carried by the microbubbles, past the lighted surfaces. Furthermore, it maintained the walls of the bioreactor free of build up of algal films that block the light, and kept algae from accumulating in stagnant "dead" zones, due to global induction of mixing.

\section{Acknowlegdements}

The authors would like to acknowledge support from the Technology Strategy Board Carbon Abatement Feasibility Studies programme (BR046G). WZ would like to acknowledge the Royal Society for a Brian Mercer Innovation Award. DJG would like to acknowledge support from the Carbon Trust. VT acknowledges support from the Czech Academy of

Science research plan AV0Z20760514. The authors thank James Hanotu for images of microbubbles from microporous ceramics and the size distribution analysis, and Yuzhen Shi, Andy Patrick, Stuart Richards, Mike O'Meara and David Palmer for technical assistance. Helpful discussions with and technical support from Bruce Adderley and Steve Woolass are acknowledged, as well as financial support to the programme from TataSteel. Similarly, Graeme Fielden and Hannah Nolan of Suprafilt, Rochdale England, are recognized for financial support and supply of the components of the microporous diffuser system. Helpful discussions with Dr Raman Vaidyanathan were appreciated.

\section{$\underline{\text { References }}$}

Adamson, A.W., Physical Chemistry of Surfaces, $5^{\text {th }}$ ed., John Wiley \& Sons, Chichester, 1990.

Brennan, L., Owende, P., "Biofuels from microalgae - A review of technologies for production, processing and extractions of biofuels and co-products," Renewable and sustainable energy review, 14, 557, 2010.

Coanda H., "Device for Deflecting a Stream of Elastic Fluid Projected into an Elastic Fluid", U. S. Patent 2,052,869, 1936. 
Coutteau P. "Micro-algae in Manual on the production and use of live food for aquaculture, Lavens P. \& Sorgeloos P. (eds.) FAO Fisheries Technical Paper No. 361. Laboratory of Aquaculture \& Artemia Reference Center, University of Gent, Belgium, 1996.

de Moris MG., Costa JAV., "Biofixation of carbon dioxide by Spirulina sp. and Scenedesmus obliquus cultivated in a three-stage serial tubular photobioreactor." Journal of Biotechnology, 129(3):439, 2007.

Doucha, J., Straka, F., Livansky, K., "Utilisation of flue gas for cultivation of microalgae in an outdoor open thin-layer photobioreactor". Journal of Applied Phycology, 17(5), 403, 2005.

Gregory W.J., Gnanamanickam E.P., Sullivan J.P., Raghu S."Variable-Frequency Fluidic Oscillator Driven by a Piezoelectric Bender”, IAA Journal 47 (11):2717, 2009.

Grammatika M, Zimmerman WB, “ Microhydrodynamics of flotation processes in the sea surface layer,' Dynamics of Oceans and Atmospheres, 34:327-348 (2001).

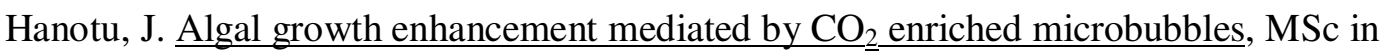
Environmental and Energy Engineering dissertation, University of Sheffield, 2009.

Kunjapur A.M. and Eldridge R.B. "Photobioreactor Design for Commercial Biofuel Production from Microalgae,” Ind. Eng. Chem. Res., 49, 3516-3526, 2010.

McKinney, J. Absorption of light by chlorophyll. Journal of Biological Chemistry 140: 315$322,1941$.

Perera P. C. , Syred N.:, "A Coanda Switch for High Temperature Gas Control", Paper 83-WA/DSC-26, American Society of Mechanical Engineers, Winter Annual Meeting, Boston 1983.

Ringleb F. O., "Separation control by trapped vortices", in: G.V. Lachman (Ed.), Boundary Layer and Flow Control, Pergamon Press, Oxford, U.K., 1961.

Spyropoulos, C. E.:, "A Sonic Oscillator," Proc. of the Fluid Amplification Symposium, Vol. III, Harry Diamond Laboratories, Washington, D.C., p. 27, 1964.

Tesař V., "A Mosaic of Experiences and Results from Development of High-Performance Bistable Flow-Control Elements", Proceedings of the Conference 'Process Control by Power Fluidics', Sheffield, Great Britain, 1975.

Tesař V., Hung C.-H., Zimmerman W., "No-Moving-Part Hybrid-Synthetic Jet Actuator", Sensors and Actuators A, 125 (2):159, 2006.

Tesař V., " Pressure-Driven Microfluidics", Artech House Publishers, Norwood, MA, USA, 2007.

Tesař, V., Travnicek, Z., Kordik, J., and Randa, Z., "Experimental Investigation of a Fluidic Actuator Generating Hybrid-Synthetic Jets," Sensors and Actuators A (Physical), 138(1):213, 2007. 
Tesař V. "Characterisation of Subsonic Axisymmetric Nozzles", Chemical Engineering Research and Design, 86: 1253, 2008

Tesař V., "Mechanism of Pressure Recovery in Jet-Type Actuators", Sensors and Actuators A-Physical, 152:182, 2009a.

Tesař V., "Enhancing Impinging-Jet Heat or Mass Transfer by Fluidically Generated Flow Pulsation", Chemical Engineering Research and Design, 87(2):181, $2009 \mathrm{~b}$.

Tesař V., Bandalusena H., "Bistable diverter valve in microfluidics", Experiments in Fluids, in Press, DOI 10.1007/s00348-010-0983-0

Warren R.W., "Negative Feedback Oscillator“, U.S. Patent No. 3158166, filed August 1962.

Yun Y-S, Lee SB, Park JM, Lee C-I, Yang J-W, Carbon dioxide fixation by algal cultivation using wastewater nutrients. Journal of Chemical Technology \& Biotechnology, 69(4), 451, 1997.

Zimmerman W.B. and J.M. Rees, “The wavelength of solitary internal waves in a stably stratified fluid layer," Nonlinear Processes in Geophysics, 11(2):165--180, 2004.

Zimmerman W.B, Tesař V, Butler SL, Bandulasena HCH, "Microbubble Generation", Recent Patents in Engineering, 2:1-8, 2008.

Zimmerman W.B., Hewakandamby B. N., Tesař V., Bandulasena H.C.H., Omotowa O.A.:"On the design and simulation of an airlift loop bioreactor with microbubble generation by fluidic oscillation“", Food and Bioproducts Processing, 97(3): 215, 2009.

Zimmerman W.B., V. Tesař, HC H Bandulasena "Towards energy efficient nanobubble generation with fluidic oscillation," Current Opinion in Colloidal and Interface Science, invited review article, in press (2011). 